NBER WORKING PAPER SERIES

\title{
THE AGGREGATE EFFECT OF SCHOOL CHOICE: EVIDENCE FROM A TWO-STAGE EXPERIMENT IN INDIA
}

\author{
Karthik Muralidharan \\ Venkatesh Sundararaman \\ Working Paper 19441 \\ http://www.nber.org/papers/w19441
NATIONAL BUREAU OF ECONOMIC RESEARCH
1050 Massachusetts Avenue
Cambridge, MA 02138
September 2013

This paper is based on the Andhra Pradesh School Choice Project that was carried out under the larger program of the "Andhra Pradesh Randomized Evaluation Studies (AP RESt)", which was set up as a research partnership between the Government of Andhra Pradesh, the Azim Premji Foundation, and the World Bank. The majority of the funding for the project was provided by the Legatum Foundation and the Legatum Institute, with additional financial support from the UK Department for International Development (DFID), and the World Bank. Muralidharan also acknowledges financial support from a National Academy of Education/Spencer Foundation post-doctoral fellowship. We are deeply grateful to M Srinivasa Rao, B Srinivasulu, S Ramamurthy, and staff of the Azim Premji Foundation for their outstanding efforts in implementing the project in Andhra Pradesh, and to DD Karopady and Dileep Ranjekar for their constant support. We thank Gautam Bastian, Vikram Jambulapati, Naveen Mandava, Jayash Paudel, and Arman Rezaee for excellent research assistance at various stages of the project. The findings, interpretations, and conclusions expressed in this paper are those of the authors and do not necessarily represent the views of the Government of Andhra Pradesh, the Azim Premji Foundation, the World Bank, or the National Bureau of Economic Research.

NBER working papers are circulated for discussion and comment purposes. They have not been peerreviewed or been subject to the review by the NBER Board of Directors that accompanies official NBER publications.

(C) 2013 by Karthik Muralidharan and Venkatesh Sundararaman. All rights reserved. Short sections of text, not to exceed two paragraphs, may be quoted without explicit permission provided that full credit, including (C) notice, is given to the source. 
The Aggregate Effect of School Choice: Evidence from a Two-stage Experiment in India Karthik Muralidharan and Venkatesh Sundararaman

NBER Working Paper No. 19441

September 2013, Revised October 2014

JEL No. C93,H44,H52,I21,O15

\begin{abstract}
$\underline{\text { ABSTRACT }}$
We present experimental evidence on the impact of a school choice program in the Indian state of Andhra Pradesh (AP) that provided students with a voucher to finance attending a private school of their choice. The study design featured a unique two-stage lottery-based allocation of vouchers that created both a student-level and a market-level experiment, which allows us to study both the individual and the aggregate effects of school choice (including spillovers). After two and four years of the program, we find no difference between test scores of lottery winners and losers on Telugu (native language) and math, suggesting that the large cross-sectional test-score differences between public and private school students on these subjects mostly reflect omitted variables. However, private schools spent significantly less instructional time on Telugu and math, and instead taught more English, science, social studies, and Hindi. Averaged across all subjects, lottery winners scored 0.13 higher, and the average causal impact on test scores of attending a private school was 0.23 . Further, the mean cost per student in the private schools in our sample was less than a third of the cost in public schools. Thus, private schools in this setting deliver (slightly) better test score gains than their public counterparts, and do so at substantially lower costs per student. Finally, we find no evidence of spillovers on publicschool students who do not apply for the voucher, or on private school students, suggesting that the positive impacts on voucher winners did not come at the expense of other students.
\end{abstract}

\author{
Karthik Muralidharan \\ Department of Economics, 0508 \\ University of California, San Diego \\ 9500 Gilman Drive \\ La Jolla, CA 92093-0508 \\ and NBER \\ kamurali@ucsd.edu \\ Venkatesh Sundararaman \\ South Asia Human Development Unit \\ The World Bank \\ vsundararaman@worldbank.org
}




\section{Introduction}

One of the most important trends in primary education in developing countries over the past two decades has been the rapid growth of private schools, with recent estimates showing that private schools now account for over $20 \%$ of total primary school enrolment in low-income countries (Baum et al. 2014). The growing market share of fee-charging private schools is especially striking as it is taking place in a context of increased spending on public education and near universal access to free public primary schools, and raises important questions regarding the effectiveness of private schools in these settings and the optimal policy response to their growth.

Opponents of the growth of private schooling argue that it has led to economic stratification of education systems and has weakened the public education system by causing elites to secede. They also worry that private schools compete by cream-skimming students, and attract parents and students on the basis of superior average levels of test scores, but that they may not be adding more value to the marginal applicant. ${ }^{1}$ Others contend that private schools in developing countries have arisen and grown in response to failures of the public schooling system, that they are more accountable and responsive to parents, that the revealed preference of parents suggests that they are likely to be better than public schools, and that policymakers should be more open to voucher-like models that combine public funding and private provision of education. ${ }^{2}$

There is, however, very little rigorous empirical evidence on the relative effectiveness of private and public schools in low-income countries. Non-experimental studies have used several approaches to address identification challenges, and have typically found that private school students have higher test scores, but have not been able to rule out the concern that these estimates are confounded by selection and omitted variables. ${ }^{3}$ Further, even experimental studies of school choice to date (from anywhere in the world) have not been able to distinguish between the effects of school productivity and changes in peer composition for voucher winners. For instance, Hsieh and Urquiola (2006) argue that Chile's school voucher program led to increased sorting of students among schools, but did not improve average school productivity.

\footnotetext{
${ }^{1}$ This concern is supported by several studies across different contexts, which find that highly-demanded elite schools do not seem to add more value to student learning (see Zhang (2014) in China, Lucas and Mbiti (2014) in Kenya, Cullen et al. (2006) in Chicago, and Abdulkadiroglu et al (2014) in Boston and New York).

${ }^{2}$ See Tooley and Dixon (2007), Muralidharan and Kremer (2008), Goyal and Pandey (2009), and Tooley (2009).

${ }^{3}$ Existing approaches to identifying the causal effects of private schools in developing countries include controlling for observables (Muralidharan and Kremer 2008), incorporating a selection correction (Desai et al. 2009), using family fixed effects and within household variation (French and Kingdon 2010), aggregation of test scores to district-level outcomes (Bold et al 2011; Tabarrok 2013), and using panel data (Andrabi et al. 2011; Singh 2014).
} 
We present experimental evidence on the impact of a school choice program in the Indian state of Andhra Pradesh (AP) that featured a unique two-stage randomization of the offer of a voucher (across villages as well as students). The design creates a set of control villages that allows us to experimentally evaluate both the individual impacts of school choice (using the student-level lottery) as well as its aggregate effects including the spillovers on non-applicants and students who start out in private schools (using the village-level lottery). The experiment was a large one that led to $23 \%$ of students in public schools in program villages moving to a private school. Participation of private schools in the voucher program was voluntary, but they were not permitted to selectively accept or reject voucher-winning students.

The main operating difference between private and public schools in this setting is that private schools pay substantially lower teacher salaries (less than a sixth of that paid to public school teachers), and hire teachers who are younger, less educated, and much less likely to have professional teaching credentials. However, private schools hire more teachers, have smaller class sizes, and have a much lower rate of multi-grade teaching than public schools. Using official data and data collected during unannounced visits to schools, we find that private schools have a longer school day, a longer school year, lower teacher absence, higher teaching activity, and better school hygiene. We find no significant change in household spending or in time spent doing homework among voucher-winning students, suggesting that the impact of school choice on test scores (if any) is likely to be due to changes in school as opposed to household factors.

At the end of two and four years of the school choice program, we find no difference between the test scores of lottery winners and lottery losers on the two main subjects of Telugu (native language of AP) and math, suggesting that the large cross-sectional test-score differences in these subjects across public and private schools (of $0.65 \sigma$ ) mostly reflect omitted variables. However, analysis of school time use data reveals that private schools spend significantly less instructional time on Telugu (40\% less) and math (32\% less) than public schools, and instead spend more time on English, science and social studies (EVS), and especially Hindi (not the main language in AP; but the most widely spoken one in India). We conduct tests in all these subjects after four years of the program and find small positive effects of winning the voucher on English $(0.12 \sigma ; p=0.098)$, and EVS $(0.08 \sigma ; p=0.16)$, and large, positive effects on Hindi $(0.55 \sigma ; p<0.001)$. Averaging across subjects, we find that students who won a voucher scored $0.13 \sigma$ higher, and students who attended private schools scored $0.23 \sigma$ higher $(p<0.01)$. 
Our finding of positive and significant test score impacts of winning a voucher is based on equal weights across subjects (including Hindi). However, even without assuming equal weights across subjects, we can still infer that private schools were more productive than public schools because they were able to achieve similar Telugu and math test scores for the lottery winners with substantially less instructional time, and use the additional time to improve outcomes on other subjects - especially Hindi. Further, the cost-effectiveness comparison is rendered stark by the fact that the annual cost per student in the public-school system is over three times the mean cost per student in the private schools in our sample. Thus, students who win a lottery to attend private schools do as well on some subjects and better on others even though the private schools spend substantially lower amounts per student.

The gains in test scores for voucher-winning students do not come at the expense of other students who may have been indirectly affected by the voucher program. Comparing across treatment and control villages, we find no evidence of spillovers on public-school students who do not apply for the voucher. We also do not find any significant difference between the test scores of applicants who are lottery losers across treatment and control villages. Finally, we find no evidence of any negative spillovers on students who started out in private schools to begin with. Taken together, we find no evidence of adverse effects on any of the groups of students who experienced a change in their peer group as a result of the voucher program.

Turning to heterogeneity, we find limited evidence of variation in program impact by student characteristics, but do find suggestive evidence of heterogeneity as a function of school and market characteristics. In particular, instrumental variable (IV) estimates suggest that students who switched from attending a public school to a Telugu-medium private school did better than those attending an English-medium one (especially on non-language subjects). ${ }^{4}$ The IV estimates have large standard errors and are not precise, but they suggest that private schools may have been even more effective when students did not experience the disruption of changing their medium of instruction. They also suggest that switching to English-medium schools may have negative effects on first-generation learners' literacy in the native language and on their learning of content in other non-language subjects. Finally, we also find suggestive evidence that the impact of the vouchers may have been higher in markets with greater choice and competition.

\footnotetext{
${ }^{4}$ We instrument for medium of instruction of the school attended (which is a choice variable) with the medium of instruction of the nearest private school to each applicant for the voucher, and the interaction of receiving the voucher and the medium of instruction of the nearest private school. See details in section 4.4.2.
} 
Since Friedman (1962), the theoretical promise that greater school choice and competition may yield better education outcomes has generated a large empirical literature, with the bestidentified studies typically using lottery-based designs to identify the impact of choice and better schooling options. ${ }^{5}$ However, the results to date on school choice are quite mixed with most studies typically finding zero to modest positive effects of receiving a voucher or attending a more selective school on test scores (Rouse and Barrow 2009 review the evidence). On the other hand, more recent studies have found significant positive effects of attending charter schools on test scores (Hoxby et al. 2009; Abdulkadiroglu et al. 2011; Dobbie and Fryer 2011).

We add to this evidence base with a large and comprehensive (in terms of data collected on intermediate inputs) study that provides the first experimental evidence on the impact of school choice, and the relative performance of public and private schools in a developing country. ${ }^{6}$ Further, our two-stage design allows us to conduct the first experimental analysis (anywhere in the world) of the spillover effects of school choice programs on non-applicants, on lottery losers, and on private school students.

More generally, our results highlight that it is essential for the school choice literature to recognize that schools provide vectors of attributes and may be horizontally differentiated in their offerings. Note that our inference regarding the relative productivity of private and public schools would have been wrong if we had not accounted for school time use patterns and had not measured outcomes on additional subjects on the basis of analyzing the school time use data. Similarly, evaluating school choice and charter school programs on a limited set of test scores (typically in math and reading) may provide an incomplete picture of the impact of such programs if they do not account for the full pattern of time use in these schools. Our suggestive evidence of heterogeneity of impact by medium of instruction further highlights the centrality of accounting for variation across schools' instructional programs for studying the relative productivity of public and private schools, and the impact of school choice. On the other hand, our results also suggest that peer-effects and spillovers may be an empirically second-order issue for the school-choice literature (especially when private schools cannot select students).

\footnotetext{
${ }^{5}$ Studies of school choice and charter schools using lottery-based designs include Howell et al. (2002), Howell and Peterson (2002), Krueger and Zhu (2004), Cullen et al (2006), Hoxby, Murarka, and Kang (2009), Abdulkadiroglu et al. (2011), Dobbie and Fryer (2011), and Wolf et al. (2013).

${ }^{6}$ Angrist et al. $(2002,2006)$ provide experimental evidence on vouchers in the middle-income setting of Colombia, and find positive effects of Colombia's PACES program. However, the program allowed vouchers to be topped up, and required students to maintain minimum academic standards to continue receiving the voucher. The estimates therefore reflect a combination of private school productivity, additional education spending, and student incentives.
} 
The policy implications of our results are particularly timely in the Indian context. Reflecting concerns of growing economic stratification in schooling, the recently passed Right to Education (RtE) Act in India includes a provision mandating that private schools reserve up to $25 \%$ of their seats for students from socio-economically disadvantaged backgrounds, with a reimbursement of fees by the government. This provision in the RtE Act could lead to India having the world's largest number of children attending private schools with public funding. It may also be the most ambitious attempt to achieve school integration across economic classes anywhere in the world. However, these large-scale changes to the education system have been mandated (and are starting to be implemented) with almost no evidence on their likely impacts. Our results are directly relevant to understanding the possible impacts of the RtE Act in India, and to informing policy approaches to the rapid growth of private schools in developing countries.

The rest of this paper is structured as follows: Section 2 describes the AP School Choice experiment (design, validity, and data collection); section 3 presents results on summary statistics of school, teacher, and household inputs into education; section 4 presents the test score results, and section 5 discusses policy implications, caveats, and directions for future research.

\section{The Andhra Pradesh (AP) School Choice Experiment}

\subsection{Background and Context}

India has the largest school education system in the world comprising around 200 million children. Primary school enrollments have steadily increased over the past two decades and over 96\% of primary-school aged children are now enrolled in school. Nevertheless, education quality is low with less than $40 \%$ of children aged 6 to 14 in rural India being able to read at the second-grade level (ASER 2013). The majority of children in rural India are enrolled in free government-run public schools (with additional benefits such as free textbooks, and mid-day meals). ${ }^{7}$ However, the public education system in India is characterized both by inefficient choices of inputs, as well as inefficient use of resources conditional on the choice of inputs. ${ }^{8}$

\footnotetext{
${ }^{7}$ Note that government-run public schools are referred to as "government schools" in India, with the term "public school" sometimes referring to elite private schools (following the British convention). We use the term "public school" throughout this paper to refer to government-run public schools following the more standard use of the term. ${ }^{8}$ As an example of inefficient choice of inputs, Muralidharan and Sundararaman (2013) show that locally-hired contract teachers are at least as effective as civil-service teachers in spite of the latter being paid five times higher salaries. The most striking evidence on inefficient use of inputs is perhaps the high rate of teacher absence. $26.2 \%$ of public-school teachers in rural India were found absent during unannounced visits to a nationally-representative sample of schools in 2003 (Kremer et al. 2005), and 23.6\% were found absent in 2010 (Muralidharan et al. 2014).
} 
A prominent trend in India in the past two decades has been that parents are enrolling their children in fee-charging private schools in increasing numbers. Annual data from the ASER reports show that $29 \%$ of children between the ages of 6 and 14 in rural India attended feecharging private schools in 2013 compared to $18.7 \%$ in 2006, pointing to a rapid growth in the market share of fee-charging private schools at a rate exceeding one percentage point per year (ASER 2013). While annual data on private school market share is not available for urban areas, this figure was estimated to be 58\% in 2005 (Desai et al. 2009) and was recently estimated to be over $65 \%$ for the medium-sized Indian city of Patna (Rangaraju et al. 2012).

The majority of these private schools are low-cost or "budget" private schools that cater to non-affluent sections of the population, and per-student spending in these schools is significantly lower than that in public schools (Tooley 2009). However, since private schools charge fees and public schools are free, students attending private schools on average come from more affluent households with higher levels of parental education (Muralidharan and Kremer 2008; also see Table A.1). Cross-sectional studies have found that students in private schools significantly outperform their counterparts in public schools, even after correcting for observable differences between the characteristics of students attending the two types of schools (Muralidharan and Kremer 2008; Desai et al. 2009; French and Kingdon 2010). Nevertheless, these studies cannot fully address selection and omitted variable concerns with respect to identifying the causal impact of attending a private school. ${ }^{9}$

The growth of private schools has led to concerns about increasing economic and social stratification in education (Srivastava 2013), and has led to calls for expanding access to private schools for all children, regardless of socioeconomic background - including experimenting with voucher-based school choice programs (Shah 2005; Kelkar 2006). India's recent Right to Education (RtE) Act includes a provision mandating that private schools reserve up to $25 \%$ of the seats in their school for students from disadvantaged backgrounds, with a reimbursement of fees by the government (subject to a maximum of the per-child spending in the public schools).

If implemented as intended, this provision in the RtE Act could lead to India having the world's largest number of children attending private schools with public funding. It may also

\footnotetext{
${ }^{9}$ Beyond selection, a major limitation in the cross-sectional comparisons is that private school students typically have two years of pre-school education (nursery and kindergarten) compared to public school students (who typically start in the first grade). Thus, comparisons of test score levels at a given primary school grade confound the effectiveness of private schools and the total years of schooling. Panel data approaches can mitigate this concern (Singh 2014) but are limited by the lack of annual panel data on test scores in representative samples.
} 
constitute the most ambitious attempt at school integration (across socio-economic classes) that has ever been attempted (analogous to school desegregation in the US). Estimating the relative productivity of public and private schools, and the spillover effects of moving children from public to private schools are therefore especially policy relevant in this setting.

\subsection{Conceptual Overview of Experiment Design}

Experimental evaluations of school voucher programs to date typically feature excess demand for a limited number of vouchers, which are allocated among applicants by lottery. Such a design creates four groups of students as shown in Figure 1 (Panel A): non-applicants (group 1), applicants who lose the lottery (group 2), applicants who win (group 3), and students in private schools to begin with (group 4). The lottery is used to estimate the impact of winning a voucher conditional on applying for it (comparing groups 3 and 2), and the impact of attending a private school (using the lottery as an instrumental variable for attending a private school).

However, even this experimental design faces two limitations: a contaminated control group, and an inability to estimate spillover effects that may negate (potential) gains estimated for voucher winners. First, the departure of some voucher winners may have additional effects on lottery losers (group 2) including changes in the peer group, changes in per-student resources (especially class size), and behavioral changes by public school teachers in response to the voucher program. These confounding factors could bias experimental studies to date, since the control group is not unaffected by the voucher program. Second, existing studies cannot experimentally estimate impacts on students left behind in public schools who did not apply for the voucher and may be worse off from the departure of highly-motivated peers (group 1), or the impact on students in private schools who may be worse off due to an influx of low-performing students from public schools (group 4). Thus, even if group 3 does better than group 2 (the focus of experimental studies to date), this may have come at the cost of poorer performance for groups 1 and 4 . Hence, a critical open question in the global literature on vouchers and school choice is that of the "aggregate impact" of such programs (Hsieh and Urquiola 2006).

The Andhra Pradesh (AP) School Choice Project (that this paper is based on) aims to address both these issues using a two-stage experiment, where villages are first randomized into control and treatment groups, after which some applicants in the treatment villages are offered vouchers using a second lottery (Figure 1 - Panel B). Since villages are randomized into treatment and control status after baseline tests are conducted and after parents apply for the voucher, 
comparing the lottery winners (3T) with lottery losers in control villages (2C) allows for an uncontaminated estimate of the impact of school choice. Thus, applicants in group $2 \mathrm{C}$ are a "pure" control group because they applied for the voucher and lost the lottery (at the village level), but nothing changed for them because there was no voucher program in their villages.

The design also allows us to estimate three sets of spillovers, which have not been possible to date. First, comparing groups 2T (control students with spillovers) and 2C (control students without spillovers), provides an estimate of the extent to which ignoring spillovers to the control group may bias existing voucher studies. Second, comparing groups 1T and 1C lets us estimate the impact of school choice programs on the students "left behind" in public schools (who for reasons of limited information or motivation choose to not apply for the voucher). Third, comparing outcomes between groups $4 \mathrm{~T}$ and $4 \mathrm{C}$ provides an estimate of whether students in private schools are adversely affected by an influx of students from public schools (which is what will happen under the school integration envisaged by the RtE Act). Overall, the key innovation in our design is that the control villages provide a "system-level" counterfactual to the voucher program enabling experimental comparisons that have not been possible to date.

\subsection{The AP School Choice Experiment}

Andhra Pradesh (AP) is the $5^{\text {th }}$ most populous state in India, with a population of 85 million (70\% rural). Recent estimates suggest that over 35\% of students in rural AP are enrolled in private schools (ASER 2013), compared to an all India average of 28\%. The Andhra Pradesh School Choice Project was implemented by the Azim Premji Foundation (one of India's leading non-profits working on education). ${ }^{10}$ The school year in AP runs from mid-June to mid-April. The AP School Choice project started in the school year 2008-09, and continued for four years (preparatory work started in the previous school year).

The project was carried out in five districts across AP over a universe of 180 villages that had at least one recognized private school. ${ }^{11}$ Baseline tests were conducted for all students in two

\footnotetext{
${ }^{10}$ The AP School Choice Project was carried out under the larger program of the "Andhra Pradesh Randomized Evaluation Studies (AP RESt)" which was set up as a research partnership between the Government of Andhra Pradesh, the Azim Premji Foundation, and the World Bank. The original state of AP was divided into two states on June 2, 2014. Since this division took place after our study, we use the term AP to refer to the undivided state.

${ }^{11}$ These were the same districts as in the overall AP RESt project, and were representative of all the three major regions of AP (Muralidharan and Sundararaman 2010, 2011, 2013); the AP School Choice Project was conducted in different sub-districts and so there was no overlap in the schools/villages across these studies.
} 
cohorts of all schools (public and private) in these villages in March-April 2008. ${ }^{12}$ This was followed by an invitation to apply for a voucher to parents of students in public schools (who had taken the baseline test) in all 180 villages. The application specified the full terms of the voucher including the fact that it would be allocated by lottery and that applying did not guarantee receipt of the voucher. The voucher covered all school fees, textbooks, workbooks, notebooks and stationery, and school uniforms and shoes, but did not cover transport costs to attend a private school outside the village and did not provide any allowance in lieu of the free mid-day meals that the public schools provide. The value of the voucher was paid directly to the school, and books and materials were provided directly to the voucher households by the schools. ${ }^{13}$

At the same time as the baseline tests, the Azim Premji Foundation (the Foundation) also invited participation in the project from private schools in the sample villages, and school participation was voluntary. The value of the voucher was set at the $90^{\text {th }}$ percentile of the distribution of the all-inclusive private school fees in the sampled villages, and schools were asked to indicate if (a) they wanted to participate in the program by being willing to admit economically disadvantaged students who would be awarded a voucher by the Foundation, and (b) if so, how many seats they could make available to voucher students in each of the two cohorts. ${ }^{14}$ The terms and conditions specified that the Foundation would directly pay the value of the voucher to the school's bank account (in three installments per year, which was the typical fee cycle of the schools). The only condition imposed on the schools was that they were not allowed to select students. If there was greater demand for a school than the number of places offered, then the school could either admit all voucher recipients who wanted to attend the

\footnotetext{
${ }^{12}$ The cohorts covered were students attending kindergarten and grade 1 in the previous school year (2007-08), and the voucher covered the entire primary education of recipients from the school year 2008-09 (from grade 1 to 5 for the younger cohort and from grade 2 to 5 for the older cohort). Baseline tests were conducted in math and Telugu (native language of AP) for the older cohort and in Telugu for the younger cohort.

${ }^{13}$ This was consistent with the standard practice that private schools had a recommended set of books, uniforms etc., which they procured in bulk and supplied to parents for a fixed fee. It was therefore easiest to have the voucher cover these payments directly as opposed to making cash payments to parents for these additional expenses. The communication regarding the voucher program and the application process was done by field staff of the Azim Premji Foundation during the summer break in May 2008.

${ }^{14}$ At the time of starting the project, the 2005 draft of the Right to Education (RtE) Act was already in circulation and private schools knew that the stipulation regarding reserving seats for economically disadvantaged children in private schools was likely to be implemented. Thus, the communications to schools regarding the project was along the lines that this was a pilot project being done by the Foundation to help the Government of AP understand the impacts and implications of implementing this provision of the RtE Act. The value of the voucher was set at the $90^{\text {th }}$ percentile of the fee distribution to ensure that the reimbursement was above marginal cost for all schools (while still being considerably below the benchmark of per-child spending in public schools).
} 
concerned school or the Foundation would conduct a lottery to allocate the places among the applicants. This was similar to admission protocols of most charter school programs in the US. ${ }^{15}$

All communications with schools (and elicitation of willingness to participate) was conducted before the village-level randomization took place. ${ }^{16}$ Once the applications were completed, 90 villages (stratified by district) were assigned by lottery to be voucher villages (Figure 1 - Panel A), while the other 90 villages continued "as usual" with no voucher program (Figure 1 - Panel B). Conditional on being a "voucher village", a second lottery was conducted to offer the vouchers to a subset of applicants. The design therefore created two lottery-based comparison groups - those who did not get the voucher due to their village not being selected for the program (group 2C in Figure 1), and those who did not get the voucher due to losing the individual level lottery conducted within voucher villages (group 2T in Figure 1).

Out of 10,935 eligible households, a total of 6,433 households applied for the voucher (59\%). A total of 3,097 households had applied in the treatment villages, from which 1,980 were selected by lottery to receive the voucher (64\%). 1,210 of these 1,980 households accepted the voucher and enrolled in a private school at the start of the project (61\%). Thus, a total of $23 \%$ of public school students in treatment villages accepted the voucher and moved to private schools, and around $8 \%$ of the students in private schools (in the two treated cohorts) were those who had transferred from the public school with the voucher. At the end of four years of the project, a total of 1,005 students continued to avail of the voucher. Figure 2 shows the program design with the actual number of students in each of the cells.

Table A.2 shows that application for the voucher, and acceptance conditional on being awarded one are not correlated with observable demographic characteristics like parental assets, education, or caste. The only observables that are correlated with application are having a private school within a radius of half a kilometer (positive), having a sibling in the public school, and being in the older cohort (both negative) which are consistent with lower (higher) switching costs. The same patterns are observed in acceptance conditional on being awarded the voucher.

\footnotetext{
${ }^{15}$ In practice, participating schools accepted all applicants who indicated a preference for the school, and the Foundation never needed to conduct a lottery to allocate students to potentially over-subscribed schools.

${ }^{16}$ The initial frame for the project was 200 villages, which was reduced to 180 after dropping villages where there was no private school willing to participate, or where the private schools did not obtain recognition at the start of the 2008-09 school year (the sample initially included villages with unrecognized schools that said that they were in the process of getting recognized, but villages where there was no school that had obtained recognition were dropped from the study universe). This was done because the Foundation did not want to put voucher-winning children in a situation where the school they went to would be shut down by the government (as the law entitles them to do).
} 
The lack of correlation between household socio-economic characteristics and voucher application or acceptance is an important result and suggests that the provision of vouchers can significantly reduce socio-economic stratification in private schools (which is one of the main concerns expressed regarding the growth of private schools - see Srivastava and Walford 2007, and Srivastava 2013 for illustrative discussions).

The allocation of villages and students to the voucher program by lottery ensured that the treatment groups and the corresponding comparison groups are not significantly different on observable characteristics including baseline test scores, parental education, assets, and caste. Table A.3 (Panel A) shows the balance between lottery winners and losers - first showing the comparison with lottery losers in the treatment villages and then showing it with lottery losers in control villages. Panel B shows the balance for the groups of students who will be used for the spillover analysis - first showing the comparison between non-applicants across treatment and control villages, and then showing it between students who start out in private schools across these villages (for the representative sample of students in these groups who we track over time).

\subsection{Data and Attrition}

We collect a rich set of survey data on school and teacher characteristics. Enumerators conducted unannounced visits to schools during the four years of the project and measured teacher absence and activity, classroom practices and processes, and school hygiene. They also conducted household surveys to obtain data on household inputs into education - including expenditure as well as student time-use data. The school surveys were carried out once a year in all schools in the 180 project villages, while the household surveys were carried out in a representative sample of households each year from all the four groups of students as indicated in Figure 2 (in both treatment and control villages).

Data on learning outcomes was collected through independent student tests conducted at the end of two and four years of the project. Tests in Telugu (native language of AP and the medium of instruction in public schools), math, and English, were conducted at the end of two and four years, while additional tests in science and social studies (EVS), and Hindi were administered at the end of four years. All subjects except Hindi were administered as written tests, whereas the Hindi tests were administered individually to students by enumerators. We attempted to administer the written tests to the full set of students who had applied for the voucher (groups 2 and 3), and a representative sample of students who had either not applied or who were in the 
private schools at the start of the project (groups 1 and 4). The Hindi tests were more expensive to conduct (since they were done individually) and were administered to a representative sample of the students who applied for the voucher. We verify that the samples are balanced across treatment and control groups for all variables in Table A.3 in all cases where we survey/test a representative sample of students (tables available on request).

Field enumerators made extensive efforts to keep track of all students who were in the frame of the study at the beginning, but some attrition was unavoidable. ${ }^{17}$ The two year attrition rate was $10 \%$ and $15 \%$ in the treatment and control groups respectively, and the four-year attrition rate was $15 \%$ and $19 \%$ in the two groups (Table A.4 - Panel A; columns 4, 5, 10, and 11). ${ }^{18}$ These differences are statistically significant (columns 6 and 12), but we find no difference in observable characteristics between the attritors across the treatment categories. We also estimate a model of the probability of attrition from the sample using a rich set of observable characteristics collected before the lottery (including baseline test scores, and household socioeconomic indicators) and cannot reject the null that the same model predicts attrition in both the treatment and control samples.

Given the balance of attrition on all observable characteristics (both individually and jointly), the estimation sample is unlikely to be imbalanced on unobservables that may be correlated with test score gains over the period of the study. Nevertheless, we test our results for robustness using both inverse-probability reweighting as well as bounding (Lee 2009). The attrition rate in the sample that is used to test for spillovers is around 33\% (Table A.4 - Panel B), but the differences between treatment and control students are not significant. ${ }^{19}$

\footnotetext{
${ }^{17}$ Most of the attrition is due to students who had migrated and could not be found, as opposed to students still attending schools but not present for testing. The initial tests at the end of two years of the project were conducted in schools, but had high attrition rates (around 40\%). This was followed by an intense effort by enumerators to track down all the students who had applied for the voucher and the conducting of an additional round of testing in each village outside school hours. This was conducted in November 2010 (around a third of the way into the third year of the program), and so the test score results corresponding to "two years" as described in the text are based on tests conducted around 2.33 years into the program. A similar protocol was followed for testing after four years.

${ }^{18}$ Note that the main treatment effects will be calculated with respect to the lottery-losers in the control villages. Columns 1-3 and 7-9 present the attrition rates relative to the lottery-losers in the treatment villages

${ }^{19}$ There is a significant difference between treatment and control groups in this sample in 1 out of 24 comparisons, which is in line with expectations in a random sample (Table A.4 - Panel B). We control for the variables compared in Table A.4 in all our estimates of program impact.
} 


\section{Results - School, Teacher and Household Inputs}

\subsection{School and Teacher Inputs}

Table 1 (Panel A) presents key summary statistics on private schools in our sample (using data from only the control villages to ensure that the descriptive statistics represent "business as usual" differences and are not affected by the treatment). ${ }^{20}$ On average, private schools in our sample are considerably larger than their public counterparts. They have a longer school year (2 working weeks or 11 days longer per year), and have considerably lower pupil-teacher ratios (around a third lower) than public schools. They are also more likely to have drinking water, functional toilets (as well as separate toilets for girls), functional electricity, and to have a computer, with the differences being quite stark on some of these measures. Public schools are more likely to have a functioning library and radio. ${ }^{21}$

Public school teachers are more likely to be male, are considerably older, have more years of teaching experience, are more likely to have completed a college degree, and are much more likely to have completed a teacher training course (Table 1 - Panel B). However, they are less likely to be from the same village as the schools that they are assigned to, and are paid six times higher salaries. This calculation understates the differences in total pay, because it does not include the discounted value of the pension and other retirement benefits that civil-service teachers obtain that are typically not available to private school teachers.

The total spending per-child spending in the public schools is over four times the mean perchild spending in the private schools in our sample (Table 1 - Panel C). ${ }^{22}$ As the discussion above suggests, the main driver of these differences in costs is the much higher salaries paid to public school teachers. However, private schools hire more teachers per student, and also have

\footnotetext{
${ }^{20}$ There are no significant differences in mean private school characteristics across treatment and control villages, but we use only the control villages for the purposes of the summary statistics. We verify that being in treatment villages does not change the average of several key school characteristics between treatment and control villages over the course of the study (results available on request). In other words, it appears as if schools used the additional resources provided by the voucher payments to either keep overall enrollments constant (by accepting voucher recipients instead of other students) or by hiring enough staff so that their characteristics (such as class size) did not change on average. More broadly, since this was a one-off experiment that was not repeated for later cohorts, we do not expect to see a significant supply-side response from private schools in response to the program (unlike what might be expected in a scaled-up steady state implementation of the RtE Act).

${ }^{21}$ The libraries referred to here are typically not separate rooms dedicated to being libraries, but are more typically a collection of books kept in a cupboard that students can use. The large prevalence of radios reflects a policy to facilitate distance education in public schools, through the distribution of radios to schools.

${ }_{22}$ Note that since salary expenditures are not reported at the school level, we compute average per-child spending in public schools from analysis of budget documents at the state-level (Dongre 2012).
} 
better infrastructure, as a result of which the differences in per-child expenditure are not as stark as the differences in teacher salaries.

In addition to reporting on measures of school and teacher quality based on their characteristics, we also measure school quality using direct observations of schools and teachers conducted during unannounced visits to the schools during the four years of the project (a representative sample of schools and teachers were observed each year). Private schools significantly outperform public schools on all measures of observed classroom processes (Table 2 - Panel A). Classrooms in private schools are significantly more likely to be engaged in active teaching ( $51 \%$ vs. $34 \%)$, have a greater likelihood of a teacher being in the classroom ( $97 \%$ vs. $92 \%$ ), and are much less likely to be multi-grade classrooms where more than one grade is taught simultaneously by the same teacher (24\% vs. $79 \%$ ). Moreover, enumerators coded teachers in private schools as being more likely to be in complete control of the class (69\% vs. $41 \%)$ and as more effective in teaching and maintaining discipline (50\% vs. $36 \%)$.

We find from observations at the teacher level (Table 2 - Panel B) that public school teachers were considerably more likely to be absent than private school teachers ( $24 \%$ versus $9 \%)$ and less likely to have been actively teaching at the point of observation ( $35 \%$ versus $50 \%$ ). ${ }^{23}$ Finally, enumerators also coded measures of school hygiene based on their observations when they entered the schools (Table 2 - Panel C) and we find that private schools are less likely to have indicators of poor hygiene such as having garbage dumped on the school premises, having stagnant water (breeding ground for mosquitos), or having a heavy presence of flies on the school premises (a common carrier of pathogens from open human and animal waste).

\subsection{Household Inputs}

In addition to school-level factors, receipt of a voucher may also change household inputs into education (Das et al. 2013; Pop-Eleches and Urquiola 2013). We collect data on time use as well as household expenditure on education from a representative sample of students, and compare these across treatment and control households. Columns 1 and 2 of Table 3 present the cross-sectional comparison of average child time use and household education expenditure between the children attending private and public schools. Columns 4 and 5 present means of

\footnotetext{
${ }^{23}$ The discrepancy between the difference in teacher absence rates (15 percentage points) and the difference in the probability that a classroom does not have a teacher (5 percentage points) is partly explained by the fact that the most common response to teacher absence in public schools is to combine grades and have all students taught by the same teacher (as seen in the much higher rate of multi-grade teaching in public schools).
} 
these same metrics for students who were awarded the voucher and those who were not. Column 6 presents the estimate of the intent-to-treat (ITT) effect of receiving a voucher on time use and expenditure, while column 7 presents the estimate of average treatment-on-treated (ToT). Thus, comparing columns 7 and 3 provides a measure of the extent to which time use and household expenditure patterns of voucher receiving students who attended a private school have converged to the typical patterns of students attending private schools.

The typical private school student spends 43 minutes more per day in school, and an additional 23 minutes per day on studying and doing homework at home (Table 3, Panel A, columns 1-3), which adds up to over an hour of extra school and study time per day and over 250 hours per year. Comparing columns 3 and 7, we see that the voucher receiving students who attend a private school have completely caught up with the typical private school student in terms of time spent in school. However, a striking result is that they do not appear to have caught up in terms of time spent studying and doing homework at home. Also, the typical private school student spends 20 minutes less per day playing with friends, while there is no reduction in time spent playing with friends for the voucher winners. These results suggest that study and play habits of voucher winners at home did not change over this period. ${ }^{24}$

Households with children attending private schools spend over five times as much money on that child's education (Table 7, Panel B, columns 1-3), which reflects private school fees and additional required expenditures on textbooks and uniforms. Public schools are free, provide free textbooks, and uniforms are optional. However, voucher-winning households spend a little less on the education (of the winning child) relative to the control group (column 7), which is consistent with the fact that the voucher pays for school fees, books, and uniforms/shoes.

In summary, household expenditure on education is slightly lower for voucher-winning children, and we find no evidence of a change in home study habits of the voucher winners. However, the average time spent in school does go up for voucher winners. Thus, any impact on test scores for voucher winners is likely to be due to changes in school-level factors as opposed to increases in household inputs.

\footnotetext{
24 Overall, around two thirds of the cost of the extra time spent in school (45 minutes/day) seems to have been borne by parents (30 minutes of reduced time on chores and work outside the home), while the remaining one third was borne by the student (15 minutes less of watching TV and free time).
} 


\section{Results - Test Scores}

\subsection{Impact of winning a voucher and attending a private school}

Our main estimating equation for the impact of receiving the voucher takes the form:

$$
T_{i s v}\left(Y_{n}\right)=\beta_{0}+\beta_{1} \cdot T_{i s v}\left(Y_{0}\right)+\beta_{2} \cdot \text { Voucher }_{i}+\beta_{Z_{i}} \cdot Z_{i}+\beta_{X_{i}} \cdot X_{i}+\varepsilon_{i s v}
$$

where $T_{i s v}\left(Y_{n}\right)$ represents normalized test scores for student $i$ in subject $s$ in village $v$, at the end of $n$ years of the experiment. Since test scores are highly correlated over time, we control for baseline test scores to increase the precision of our estimates. ${ }^{25}$ We also include a set of district fixed effects $\left(Z_{i}\right)$ to absorb geographic variation and increase efficiency, and to account for the stratification of the village-level lottery at the district level. The main estimate of interest is $\beta_{2}$, which provides an unbiased estimate of the impact of winning a voucher on test scores (the intent-to-treat or ITT estimate) since the voucher was assigned by lottery. We estimate $\beta_{2}$ both with and without controlling for household socioeconomic characteristics $\left(X_{i}\right)$ shown in Table 1.

As described in section 2, a key feature of our design is the ability to estimate the impact of winning the voucher relative to the control group in control villages. The estimation sample therefore includes the applicants who won the voucher lottery, and applicants whose villages were not selected (by lottery) to receive the voucher. The estimation sample does not include the applicants who lost the lottery but were in treatment villages (we use this sample later when analyzing spillover effects). Test scores are normalized relative to the distribution of the publicschool students in the control villages on each test, since these students represent the "business as usual" distribution of test scores. Standard errors are clustered at the village level to account for common shocks to test scores that may occur at the village level.

We estimate the impact of attending a private school using the offer of a voucher as an instrumental variable for attending a private school, where the second stage equation is:

$$
T_{i s v}\left(Y_{n}\right)=\beta_{0}+\beta_{1} \cdot T_{i s v}\left(Y_{0}\right)+\beta_{2} \cdot \text { Private_School }_{i}+\beta_{Z_{i}} \cdot Z_{i}+\beta_{X_{i}} \cdot X_{i}+\varepsilon_{i s v}
$$

and the endogenous regressor Private_School $i$ is instrumented for with the first-stage equation:

$$
\text { Private_School }_{i}=\gamma_{0}+\gamma_{1} \cdot T_{i s v}\left(Y_{0}\right)+\gamma_{2} \cdot \text { Voucher }_{i}+\gamma_{Z_{i}} \cdot Z_{i}+\gamma_{X_{i}} \cdot X_{i}+\varepsilon_{i s v}
$$

These results are presented in Table 4 for test scores at the end of two and four years of the program, with Panel A showing the impact of being awarded a voucher and Panel B showing the

\footnotetext{
${ }^{25}$ The default baseline score that we control for is the score on the same subject, but in cases where no baseline test was conducted in the same subject, we control for the mean normalized test score across all subjects for which a baseline test was available (which provides a measure of baseline ability, and increases precision).
} 
impact of attending a private school. We report the results for each subject separately, as well as averaged across subjects. ${ }^{26}$ Results in Table 4 includes the controls shown in Table 1 (for greater precision), but they are unchanged without the controls. ${ }^{27}$

At the end of two and four years of the program, we find that voucher lottery winners had slightly lower scores on Telugu and math than lottery losers (not significant - columns 1, 2, 5, and 6), and higher scores in English ( $0.19 \sigma$ after two years, $p=0.02$, and $0.12 \sigma$ after four years, $p=0.098$; columns 3 and 7). The average impact across the three subjects that were assessed at the end of two years was close to zero (Table 4 - column 4).

These results might seem surprising since private schools perform better on most measures of effort - including having a longer school year and school day, substantially lower pupil-teacher ratios, and higher levels of teacher attendance and effort. On the other hand, the teachers in the private schools are less likely to have a college degree or a teacher training credential. They are also less experienced, and paid much lower wages. So these factors may offset each other and produce a net effect of close to zero. Overall, these results suggest that the large cross-sectional differences in math and Telugu test scores (of $0.65 \sigma$ ) shown in Table A.1 are mostly driven by omitted variables and not by differential effectiveness of public and private schools.

However, in addition to facilities, teachers, and teacher activity levels, a key determinant of education outcomes is instructional time, and in particular the allocation of instructional time across different subjects. ${ }^{28}$ We present data from school time tables in Table 5, and see that private schools have sharply different patterns of time allocation than public schools. In particular, they allocate a lot less time per week to Telugu and math, which are the two main subjects taught in the public schools - accounting for over 500 minutes/week, and around $28 \%$ of total instructional time each. Private schools spend around 200 minutes less on Telugu and 160 minutes less on math per week ( $40 \%$ and $32 \%$ less instructional time respectively). On the other hand, they spend significantly more time on other subjects such as English ( $\sim 90$ minutes/week), social studies ( $\sim 65$ minutes/week), science ( $\sim 100$ minutes/week), Hindi ( $\sim 215$ minutes/week), and computer use ( $\sim 45$ minutes/week). They also spend an hour/week more on "other" periods

\footnotetext{
${ }^{26}$ This procedure is similar to that of Kling, Liebman, and Katz (2007) for the analysis of programs with multiple outcomes. Olken, Onishi, and Wong (2012) use a similar approach in a recent field experiment in Indonesia that studied multiple outcomes across health and education.

${ }^{27}$ The only result whose significance changes without socioeconomic controls (that improve precision) is the 4-year impact on English that moves from a $p$-value of 0.098 (with controls) to a $p$-value of 0.113 (without controls).

${ }^{28}$ We thank Mark Jacobsen for this comment while discussing the two-year results, which prompted us to collect and analyze school time table data, and test additional subjects at the end of Year 4 based on the time table data.
} 
which include arts, crafts, sports, and study hall. Overall, we see that the three subjects that were tested at the end of two years of the program account for $70 \%$ of the instruction time in public schools, but for less than $50 \%$ of that in the private schools.

Thus, limiting our analysis to these subjects may provide an incomplete picture of the impact of the voucher. Based on the time table data, we also conducted tests in science/social studies (EVS) and Hindi after four years of the voucher program. ${ }^{29}$ While this still does not account for all the subjects (computer use for instance), the tested subjects now account for over $80 \%$ of instructional time in both types of subjects and are also closer to being equal across school types ( $81 \%$ for private and $85 \%$ for public schools). The full set of test score results are presented in Table 4 - columns 5 to 10 . Voucher-winning students score slightly better in EVS $(0.08 \sigma ; p=$ 0.16), and much better in Hindi $(0.55 \sigma, p<0.001)$. Averaging across all subjects, students who won a voucher score $0.13 \sigma$ better than those who did not, and the causal impact of attending a private school is estimated as $0.23 \sigma$ (both with $p<0.01$ ).

Since the overall positive effects of receiving a voucher are mainly driven by gains in Hindi, and since public schools do not teach Hindi, we analyze the Hindi results in more detail at the individual question level (by skill) to better understand what the program impact means in terms of actual ability to use Hindi. We present these results in Table A.5, and see that attending a private school more than doubles the probability of students reading letters correctly, and more than triples the probability of being able to read words, sentences, and paragraphs.

While we follow Kling, Katz, and Liebman (2007) in reporting mean test score impacts across subjects, our finding of a positive impact of receiving a voucher (and attending private schools) depends on assuming equal weights across subjects. However, while views on optimal weights across subjects may vary, we can unambiguously infer that private schools are more productive, because they deliver similar outcomes in Telugu and math with less instructional time, and use the extra time to improve test scores in other subjects (especially Hindi).

\footnotetext{
${ }^{29}$ Under the government syllabus for primary schools, science and social studies are taught jointly under the subject title of "environmental studies" (EVS). The tests we conduct follow the curriculum and are therefore analyzed and reported jointly as EVS. The EVS tests were administered in a standard written format. Hindi is not taught in the public schools, and so we could not administer a written test (which would result in more children being coded as scoring zero in Hindi relative to their true level of competence). Enumerators therefore administered individual oral tests to a representative sample of the universe of voucher applicants (which was balanced between treatment and control categories on all observables). The test follows the same format as that administered by the non-profit Pratham in their annual surveys of learning levels implemented across India (ASER 2013) and is therefore comparable with a benchmark measure of competence that has been widely used in India in the recent past.
} 


\subsection{Robustness to attrition}

The main threat to the results above is from the differential attrition noted in Table A.4. As discussed in section 2.4, we verify that our results are robust to this concern using two different procedures. In Table 6 - Panel A, we report the ITT effects of winning a voucher using inverse probability reweighting to account for the differential probability of attrition based on observables, and see that doing so barely changes the estimated effects presented in Table 8 Panel A. As we will see in section 4.4.1, there is very limited evidence of heterogeneous treatment effects by baseline student characteristics, and it is therefore not surprising that inverse probability reweighting does not change the main estimates.

A more conservative approach to the differential attrition rates between treatment and control groups is to compute bounds based on Lee (2009). We calculate these bounds and show the widened $95 \%$ confidence intervals as a result of the procedure in Table 6 - Panel B. The results are all robust to implementing these bounds. The point estimates of the impact on math, Telugu, and EVS continue to be insignificant; the estimated impact on English is now insignificant (not surprising, given its marginal significance in Table 4); and the estimated impact on Hindi is large enough that its significance is not affected by using the more conservative confidence intervals implied by the Lee bounds. The overall ITT estimate (averaged across subjects - column 10) also continues to be significant (though at the 5\% and not at the $1 \%$ level as in Table 4).

\subsection{Spillover Effects}

An important concern in the global school choice literature is that positive estimated effects of vouchers from experimental studies may be overstating the benefits of private schools because these estimates do not account for potential negative spillovers to students in the public schools who do not apply for the voucher or for potential negative spillovers on the students who start in the private schools, and who are exposed to lower-scoring peers from public schools as a result of the voucher program (Hsieh and Urquiola 2006). Our two-stage design experimental design allows us to estimate these spillovers. We calculate three different sets of spillovers as described in section 2.2, and the estimating equations all take the same form as (1), but the right-hand side variable of interest is now an indicator for being in a voucher village. The estimation samples comprise the concerned group for whom we want to estimate the spillovers (lottery losers, nonapplicants, and students attending private schools before the school choice program) from both 
treatment and control villages. The village-level lottery ensures that we obtain unbiased reduced form estimates of these three spillovers.

Table 7 - Panel A compares the within-village control group to the across-village control group. Note that the former is the traditional control group used in typical experimental studies of school choice (the lottery losers in the treatment villages) and that this sample has not been used so far in any of the analysis due to the possibility of spillovers as discussed in section 2.2. We find no difference whatsoever between the groups, and the combined effects across subjects are not only insignificant but close to zero. ${ }^{30}$ Panel B estimates if there were any spillovers on non-applicants and we again find no significant effects on either individual subjects or on the aggregate test scores across subjects. Thus, even though the literature has often worried about the possibility of negative spillovers on students who are "left behind" in public schools in response to voucher programs, these spillovers were not empirically salient in our setting even though a large fraction (23\%) of public school students moved out to private schools. ${ }^{31}$

In the Indian context, a greater concern has been the possibility that the Right to Education Act clause on quotas in private schools would lead to negative spillovers on the students who start out in the private schools (see Shah 2012 for an example). We estimate these spillovers in Panel $\mathrm{C}$ and find that there are no significant negative spillovers on the students who were in private schools to begin with. In addition to these average spillover effects on private school students in the exposed cohorts, we also estimate the extent of spillovers as a function of the number of voucher-winning students who join a particular private school.

Since this is endogenous, we first construct a measure of "potential exposure to voucher students" for each private school (in both treatment and control villages) as the number of voucher applicants for whom it is the nearest private school. We then construct an instrumental variable for the number of voucher-winning students who join any given private school by interacting the "potential exposure" with the (randomly-determined) fraction of these students who win a voucher. The instrument will be zero for all private schools in control villages (where no vouchers were awarded), and can vary across private schools in treatment villages. We

\footnotetext{
${ }^{30}$ Our not finding any significant spillovers here suggests that the potential contamination of the "typical" control group (as discussed in section 2.2) in existing voucher studies is likely to be an empirically second-order issue.

${ }^{31}$ Of course, the estimated 'non-effect' is a reduced form estimate that combines factors which could potentially hurt the students left behind (loss of motivated peers) as well as those that could help them (smaller class sizes if teacher allocations did not fully adjust to the departure of the voucher students, and potential positive teacher effort response to competition). We do not have enough power to explore these channels with adequate precision, but we do provide the first experimental reduced form estimates of these spillovers.
} 
present the IV estimates of spillovers on private school students as a function of the number of voucher students received by the school in Table A.6, and again find no impact on the test scores of students who started out in private schools. ${ }^{32}$ While set in India, these results are consistent with those reported in Angrist and Lang (2004) who similarly find negligible impacts on white students from the school desegregation conducted under the Boston Metco Program.

Taken together, our results suggest that the positive test score effects for voucher winners are not achieved at the cost of negative outcomes for any other group of students who may have been indirectly affected by the voucher program. Of course, our results do not imply that peer effects and sorting never matter for evaluations of school choice. But they do suggest more broadly that while spillovers are an important theoretical concern in the school choice literature, they do not appear to be empirically first-order in our context, and may not be so for lotterybased studies of school choice in programs that do not allow private schools to select students. ${ }^{33}$

\subsection{Heterogeneous effects}

\subsubsection{Heterogeneous effects by student characteristics}

We test for heterogeneity of the impact of the voucher program along several student characteristics including baseline scores, gender, caste, parental literacy and affluence, cohort, and religion, using a standard linear interaction specification of the form:

$$
T_{i s v}\left(Y_{n}\right)=\beta_{0}+\beta_{1} \cdot T_{i s v}\left(Y_{0}\right)+\beta_{2} \cdot \text { Voucher }_{i}+\beta_{3} \cdot \text { Characteristic }_{i}+\beta_{4} \cdot \text { Voucher }_{i} \cdot
$$

Characteristic $_{i}+\beta_{Z_{i}} \cdot Z_{i}+\varepsilon_{i s v}$

where the parameter of interest is $\beta_{4}$ which estimates the extent to which the impact of the vouchers is different for students with the concerned characteristic.

Table 8 reports estimates of $\beta_{4}$ over two and four years. The main result is the lack of any consistent evidence of heterogeneous effects along most student characteristics. In particular, the

\footnotetext{
${ }^{32}$ The instrument is relevant because distance is a strong predictor of primary school choice (first stage F-statistic is over 45 in Table A.6). We present the first stage regression in Table A.7 and see that the instrument strongly predicts the number of voucher students attending any given private school. Further, the village-level randomization (after inviting applications) allows us to define the "potential exposure" variable for every private school in both treatment and control villages. Thus, an alternative approach to using a linear IV for estimating spillovers (as shown in Table A.6) is to restrict our spillover analysis in Table 7 - Panel C to private schools (in treatment and control villages) with higher potential exposure to voucher students. We re-estimate the spillover effects reported in Table Panel C in samples restricted to the top $50 \%$ of private schools (by potential exposure to voucher students) and also the top 25\%, and still find no evidence of spillover effects (results available on request).

${ }^{33}$ Macleod and Urquiola 2012 develop a model of school choice under different selection regimes and show that many of the potential gains of choice and competition may not materialize in systems where private schools are allowed to select students, while also showing that choice and competition will typically improve outcomes if private schools are not allowed to select their students.
} 
baseline score can be treated as a summary statistic of educational inputs that students had received up to the point when they enter the study, and the lack of any differential treatment effects by baseline score suggests that the impacts of the program were broad based. The one group that seems to benefit significantly more from the voucher program are Muslim students, who are one of the most educationally disadvantaged groups in India (Sachar et al. 2006). ${ }^{34}$ These results are consistent with those found in the US by Howell and Peterson (2002) who report that educationally-disadvantaged groups gain the most from school choice programs.

\subsubsection{Heterogeneous effects by school characteristics}

Our experiment was not designed to identify heterogeneous effects by school characteristics, ${ }^{35}$ but we report some suggestive results that are likely to be important for future research designed explicitly to study such heterogeneity. In particular, a key feature of private school heterogeneity in India is the medium of instruction. All public schools in our sample teach in Telugu, whereas over half the private schools use English as the medium of instruction. The high actual and perceived returns to English in India have led to growing demand for Englishmedium private schools. ${ }^{36}$ At the same time, it is possible that switching to being taught in English may be disruptive to the learning of voucher-winning students (many of whom are firstgeneration learners with illiterate parents). Thus, studying heterogeneous impacts of attending private schools as a function of the medium of instruction is especially important in this context.

Since the choice of school attended (and its medium of instruction) is endogenous, we use the medium of instruction of the nearest private school to each applicant household, and its interaction with the receipt of the randomly-assigned voucher as instruments for the medium of instruction of the private school attended. We define the following variables of interest:

$A_{-} E M_{-} P S_{i}=$ Student $i$ attends an English Medium Private School

$A_{-} T M_{-} P S_{i}=$ Student $i$ attends a Telugu Medium Private School

\footnotetext{
${ }^{34}$ Since we are testing heterogeneity across several covariates in Table 10, we need to be cautious in inferring heterogeneity since significant results could simply be reflecting sampling variation. However, we can be more confident in the inference that Muslim students benefit more from the vouchers because we see significant positive effects for Muslim students in both the two-year as well as the four-year data and this is seen for every subject at the two-year point, and three out of five subjects after four years.

${ }^{35}$ Note that this is true of the experimental school choice literature in general, because even when a voucher is randomly assigned, the school attended is typically not. Indeed, the logic of school "choice" is based to a considerable extent on enabling better student-school matching on unobserved characteristics.

${ }^{36}$ Munshi and Rosenzweig (2006), Azam, Chin, and Prakash (2011), Chakraborty and Kapur (2012), and Shastry (2012) all find significant positive labor market returns in India to knowledge of English. Several journalistic accounts and qualitative studies have noted the high perceived returns to English among parents, and the growing demand for English medium schools in India (see Bajaj and Yardley 2011, and Meganathan 2011 for examples).
} 
$N_{-} P S_{-} E M_{i}=$ Nearest Private School to student $i$ teaches in English Medium

$N_{-} P S_{-} T M_{i}=$ Nearest Private School to student $i$ teaches in Telugu Medium

and are interested in estimating $\beta_{2}$ and $\beta_{3}$ in the second-stage equation:

$$
T_{i s v}\left(Y_{n}\right)=\beta_{0}+\beta_{1} \cdot T_{i s v}\left(Y_{0}\right)+\beta_{2} \cdot A_{-} E M_{-} P S_{i}+\beta_{3} \cdot A_{-} T M_{-} P S_{i}+\beta_{X_{i}} \cdot X_{i}+\varepsilon_{i s v}
$$

where the endogenous variables are $A_{-} E M_{-} P S_{i}$ and $A_{-} T M_{-} P S_{i}$, and the first-stage equations are:

$$
\begin{aligned}
& A_{-} E M_{-} P S_{i}\left(\text { or } A_{-} T M_{-} P S_{i}\right)=\gamma_{0}+\gamma_{1} \cdot T_{i s v}\left(Y_{0}\right)+\gamma_{2} \cdot N_{-} P S_{-} E M_{i}+\gamma_{3} \cdot N_{-} P S_{-} T M_{i}+\gamma_{4} \cdot \\
& \text { Voucher }_{i} \cdot N_{-} P S_{-} E M_{i}+\gamma_{5} \cdot \text { Voucher }_{i} \cdot N_{-} P S_{-} T M_{i}+\gamma_{X_{i}} \cdot X_{i}+\varepsilon_{i s v}
\end{aligned}
$$

We use (6a) and (6b) to instrument for the two endogenous variables in (5), and present the two first-stage regressions in Table A.8. The main parameters of interest $\left(\beta_{2}\right.$ and $\left.\beta_{3}\right)$ from the IV estimation of (5) are presented in Table 9 - Panel A. A more conservative approach is to use only the interactions as instruments, and we present the results from this specification in Table 9 - Panel B. ${ }^{37}$ The estimation sample is the same as that in Table 4, and comprises the voucher lottery winners in the treatment villages, and the lottery losers in the control villages. ${ }^{38}$

At the end of four years of the voucher program, we find that the causal impact of attending an English-medium private school varies sharply by subject, with students doing worse (than staying in the public school) in Telugu, math, and EVS; but much better in English, and Hindi. The mean impact across subjects is positive $(0.22 \sigma)$ but not significant. On the other hand, the estimated impact of attending a Telugu-medium private school is positive for every subject, and the mean impact across subjects is positive $(0.53 \sigma)$ and significant (Table 9 - Panel A). The IV estimates in Table 9 have large standard errors, and are much less precise than the main estimates in Table 4. Nevertheless, some suggestive patterns emerge in the results.

The first is that the causal impact of attending a Telugu-medium private school (for students who start out in public schools - which all teach in Telugu medium) on test scores in Telugu, math, and EVS appears to be greater than that of attending an English-medium private school (pvalue of $0.15,0.13$, and 0.06 respectively). The second is that there appears to be a negative impact of switching the medium of instruction on the learning of content in non-language

\footnotetext{
${ }^{37}$ Since the location decisions of English and Telugu medium schools may vary, the most conservative IV strategy is to use only the interactions as instruments (because these are comparing similarly located schools across treatment and control villages - which are chosen randomly). However, as we see in Table A.9, there is no difference in mean baseline scores of voucher applicants as a function of whether their nearest private school is in English or Telugu medium. So, our default specification uses all four instruments (for greater precision) and includes all variables in Table A.9 as controls (Panel A), but we also report results with the more conservative IV strategy (Panel B).

${ }^{38}$ However, we have around 7\% fewer observations in Table 9 than in Table 4 due to missing household GPS data. The results in Table 4 are unchanged when estimated in this truncated sample (available on request).
} 
subjects. We see this most clearly in the last column of Table 9 - Panel A, where we present the mean treatment effects across math and EVS (which are the two content subjects, while the other three are language subjects). The difference in mean test scores across medium of instruction is $0.77 \sigma$, which is a very large effect $(p=0.07)$. The third is that private schools appear to be even more effective than suggested by the estimates in Table 4 (a mean treatment effect of $0.53 \sigma$ across subjects as opposed to $0.23 \sigma$ ), when their students are not also going through the disruption of switching their medium of instruction. ${ }^{39}$

These results are only suggestive, and have several caveats. First, they are highly imprecise. Using a more conservative IV strategy (reported in Table 9 - Panel B), we find similar estimates, but the standard errors are too large for meaningful inference. Second, even with a precise IV estimate, the medium of instruction will be correlated with other school characteristics.

However, we see that on average, the English-medium schools have superior indicators of school quality - including facilities; teacher experience, qualifications, and salary; and annual fees charged per child (Table A.10). Since our main result in Table 9 is that Telugu-medium private schools appear to be more effective than English-medium ones, the superior input-based quality indicators of the English-medium schools, suggest that the differences reported in Table 9 may be a lower bound on the relative advantage of native-language versus English-medium instruction (for the population of public school students who applied for the voucher).

These results are consistent with the education psychology literature, which suggests that first-generation learners may be better off being taught in their native language, which can be reinforced at home (see Abadzi 2006 for a summary). Qualitative interviews by enumerators with teachers and parents, suggest that one plausible reason for adverse effects of shifting to an English-medium private school is that these schools use textbooks written in English for teaching non-language subjects such as math, and EVS, and that reading textbooks in English was much more difficult for students shifting from public schools.

In the development economics literature, Ramachandran (2012) provides recent evidence from Ethiopia showing that a switch to mother-tongue instruction for primary school led to a

\footnotetext{
${ }^{39}$ Recall that the point estimates are relative to attending public schools, and the impacts on Telugu and math reflect both the potentially higher private school "productivity effect", and the lower instructional time allocated to these subjects in the private schools. The results on EVS on the other hand reflect both the productivity effect and additional instructional time, and it is therefore not surprising that the estimated effects on EVS are much larger (when the medium of instruction is not disrupted). However, our focus in this table is on the relative impact of Telugu and English medium private schools (and less on the subject-level point estimates relative to public schools).
} 
significant increase in education attainment. ${ }^{40}$ Jain (2014) examines historical data from colonial India and finds that linguistically-mismatched districts (where the official language did not match the local language) had lower rates of literacy and college graduation results. Our results are consistent with these findings in aggregate data, and highlight the importance of more wellidentified research to directly estimate the impact of the medium of instruction on test scores. ${ }^{41}$

\subsubsection{Heterogeneous effects by market characteristics}

The market-level experimental design allows us to test whether students who have greater choice among schools benefit more from a voucher (Hoxby 2000). We use the distance data described above to calculate the number of private schools within a one-kilometer radius of each voucher applicant. Our measure of choice and competition is constructed separately for each student, and can therefore generate variation at the student-level even for students living in the same village. We estimate the relationship between the number of schools in an applicant's choice set and test scores, both parametrically and non-parametrically. For the first, we use a linear interaction of voucher receipt and the number of schools in the choice set in a specification similar to (4). For the second, we estimate equation (4) with the "characteristic" being whether the number of schools a student has in her choice set is in the top $25 \%$, top $10 \%$, or top $5 \%$ of the distribution of the number of schools.

These results are presented in Table 10, and we find no significant effect of choice and competition when estimated with a linear interaction between voucher receipt and the number of schools in a student's choice set within one kilometer. However, while conducting the study in a rural sample allows us to study spillovers by randomizing across villages, a limitation is that around $50 \%$ of voucher applicants have only $0(27 \%)$ or $1(21 \%)$ private school within a onekilometer radius. Thus, the extent of choice and competition between private schools is quite limited for many of the voucher applicants.

The non-parametric estimates might therefore be more appropriate in this context, and they provide some suggestive evidence of the benefits of greater choice and competition, since we

\footnotetext{
${ }^{40}$ The estimated magnitudes are large, and suggest that the change led to an increase of one year of primary schooling and 1.18 years of total schooling in the affected cohorts (which is one-third of the mean years of schooling in Ethiopia at the time). It is also interesting to note that the estimated effects are all on the intensive margin of years of education completed, suggesting that the mechanism of impact is not through increased likelihood of enrollment but more likely through better learning and lower resulting drop-out rates.

${ }^{41}$ See Grewal (2008) for a rich discussion of the ethical and economic considerations regarding language policy in a globalized world where high returns to English prompt students in non-English speaking countries to learn English, but often at considerable cost (both financial and opportunity costs of learning their own languages better).
} 
find that voucher winners do significantly better when they have six or more schools within a one kilometer radius of where they live (Table 10). We find evidence of larger impacts in areas with more choice and competition in both the two-year and the four-year results, suggesting that the heterogeneity is likely to be real and does not just reflect sampling variation. Further, we find similar results when we consider heterogeneous impacts as a function of the number of private schools in a half-kilometer radius and with the total number of schools in a half or onekilometer radius and not just the number of private schools (available on request).

However, these results are suggestive, since they are only significant in markets representing the top 5\% of the distribution of the extent of choice and competition, and the rural setting may not be the best one to study heterogeneous impacts of school choice as a function of the extent of choice and competition. However, urban India has much greater population and school density, and a recent geo-coded school census in the city of Patna found that there are between 9 and 93 private schools within a one kilometer radius of every public school, with the median being greater than 50 (Rangaraju et al. 2012). ${ }^{42}$ Our results therefore suggest that the impact of a school voucher program may be considerably larger in such a context. This is an important area for future research.

\subsection{Cost Effectiveness}

The combination of test score results (Table 4) and school time table data (Table 5) already show that private schools are more productive than public schools because they are able to produce similar levels of test scores in math and Telugu using substantially less instructional time and use the extra time to produce higher test scores in other subjects - especially Hindi. Further, the results in Table 9 suggest that private schools may be even more productive when students attending them are not experiencing the disruption of switching their medium of instruction. Finally, it is worth highlighting that the average cost per-student in the private schools in our sample is less than one-third of the per-student costs in the public schools (Table 1 - Panel C) and that the value of the voucher was only around $40 \%$ of the per-student costs in the public schools. Thus, private schools produce better academic outcomes at lower cost and are unambiguously both more productive and cost-effective than public schools in India.

\footnotetext{
${ }^{42}$ Patna is the capital of the state of Bihar with a population of 1.7 million and population density comparable to other large cities in India.
} 


\section{Discussion and Conclusion}

We present evidence from the first experimental evaluation of the impact of a school choice program and the first experimental evidence on the relative effectiveness of private and public schools in a low-income country. The two-stage experimental design allows us to not only study the impact of receiving a voucher and attending a private school, but also to estimate spillovers on non-applicants and students in private schools.

Our results on private school productivity suggest that it may be possible to substantially increase human capital formation in developing countries like India by making more use of private provision in the delivery of education. The differences in productivity by type of school management are consistent with the evidence in Bloom and Van Reenen (2010) documenting that "government-owned firms are typically managed extremely badly". The costs of low productivity in education delivery may be especially high in low-income settings where low levels of human capital are likely to be barriers both to economic growth and to the inclusiveness of growth, and where fiscal constraints limit the total spending on education.

Our results showing no significant spillovers on private-school students from receiving voucher recipients from public schools suggest that it may be possible to achieve greater levels of social integration in private schools, as envisaged by the RtE Act, without the efficiency costs that opponents of integration are concerned about. While the estimates are clearly most relevant to the Indian context, they are consistent with similar findings showing low academic costs to advantaged students from school integration policies in the US (Angrist and Lang 2004).

Finally, our demonstration of the centrality of accounting for patterns of time use in evaluating the effectiveness of private schools are perhaps the most general result for the global literature on school choice. On the one hand, studies of vouchers and school choice that find no effects on test scores may understate the benefits by not accounting for other subjects that the private (or elite public) schools may be teaching. On the other hand, studies of charter schools finding positive effects on test scores may overstate the benefits if charter schools focus more on scores on high stakes tests and divert instructional time away from other subjects. More broadly, schools provide vectors of outcomes and may be horizontally differentiated in their offerings, which makes it difficult to compare outcomes across school types. In the absence of data on long-term outcomes such as employment and wages, it is important for education researchers to 
devise, test, and validate more content-neutral measures of learning that may enable meaningful comparisons of outcomes across varying instructional programs.

The policy implications of our results for education in India are particularly timely. The provision in the RtE Act for $25 \%$ reservation in private schools for disadvantaged students (with the government reimbursing private school fees) has been highly controversial and contested all the way up to the Supreme Court of India. Our results suggest that this provision is likely to not only reduce social stratification at limited cost to current students in private schools, but also likely to increase average productivity in the education sector by increasing the share of private schooling. This may thus be a rare example of a policy that improves equity, and efficiency, and does so at a lower cost than the status quo. ${ }^{43}$

Nevertheless, there are important caveats to the broad implication that greater private sector participation in education production (supported by public funding, and featuring enhanced school choice) would improve the productivity of human capital formation. The first is that the private schools in our sample did not on average improve outcomes in math and the native language (even though they spent less time and money, and were as a result more productive). It is important to highlight that our results do not imply that increasing the time or money spent on instruction in these subjects in private schools will lead to a linear (or even concave) increase in learning outcomes (we have no evidence on this). For instance, if the voucher value were to be increased to equal the level of per-student spending in the public schools, it is possible that the private schools may respond by improving aspects of the school that are more visible to parents and improve their marketing prospects rather than investing in more effective teaching.

We see an illustration of this issue when we consider the question of why private schools choose the allocation of instructional time that they do. In particular, students may be better off if private schools used their higher productivity to spend more time on the native language to help students reach grade-appropriate reading levels in at least one language, as opposed to low levels of knowledge in three languages. ${ }^{44}$ Qualitative interviews with head teachers suggest that

\footnotetext{
${ }^{43}$ Note that reimbursements to private schools are capped at the per-child spending in public schools. The increased social integration across economic classes may have broader social benefits as well. For instance, Rao (2014) finds evidence in Delhi that exposure to economically disadvantaged students increased pro-social preferences and behavior among privileged children attending private schools.

${ }^{44}$ The literature on early childhood development in low-income countries suggests that returns to language competence are convex for the first language, because of the importance of being able to "read to learn" in at least one language (Abadzi 2006). The majority of public school students in AP are far behind grade-level competences in Telugu and math (Muralidharan and Zieleniak 2014), and cannot typically read fluently even in Telugu, which is
} 
an important reason for this is that the low-cost private schools in our sample typically copy the curriculum of elite private schools, which feature the three-language formula that is typical of the education that elites in India receive. ${ }^{45}$ Given the socially-aspirational nature of private school attendance (see Bajaj and Yardley 2011), the management of private schools we interviewed stated that it would be difficult for them to remain competitive if they did not follow the curriculum that was standard among elite private schools (even if this curriculum was not optimal for the learning of the typical student attending a low-cost private school). ${ }^{46}$

This discussion points to the second caveat, which is that there may be a trade-off between a libertarian approach to school choice that believes that parents will make optimal schooling choices for their children and a paternalistic one that believes that parents may make misguided evaluations of school quality based on factors that may not contribute to more effective learning (such as buildings and facilities, and levels of test scores of other students). Our results unambiguously establish that private schools are more productive and cost effective than public schools from the perspective of a social planner. But, it is not obvious that they represent a better value for the marginal parent who is paying out of pocket for private schools over a free public school. Since test scores did not improve in math and Telugu, the marginal parent would have to place a high value on Hindi scores to justify paying out of pocket for the typical private school in our sample. While, we cannot rule out this possibility (or that parents valued other non-academic aspects of private schools), it is also possible that parents were not able to easily determine the effectiveness of schools at improving learning outcomes, and it may be important to provide better and easily understandable information on determinants of education quality to schools and parents (Hastings and Weinstein 2008; Andrabi et al. 2013).

A final caveat is that the social efficiency gains from the greater productivity of private schools can be negated if the steady state system of allocation of students to schools features

their native language (ASER 2013). Since the mean impact on Telugu scores of going to private schools was zero, it is likely that the absolute level of competence in any language is low for voucher winners.

${ }^{45}$ The three language formula aims to teach the state language, the national language (Hindi) and a global language (English) that also serves as a lingua-franca between Indian states given the history of resistance to Hindi in some non-Hindi speaking states of India. This is an onerous expectation relative to most countries, but is standard among most Indian elites - especially those in non-Hindi speaking states such as Andhra Pradesh.

${ }^{46}$ Of course, it is also likely that knowledge of an additional language like Hindi (the most widely-spoken Indian language, and the fourth most spoken language in the world with over 500 million speakers) would have positive labor market returns (especially with growing migration of workers across Indian states). But, it is not clear that these returns are higher than those from increasing competence in the native language to enable better learning of core content subjects. This is an important area for future research. 
high degrees of selectivity by schools (see Macleod and Urquiola 2012 for a theoretical treatment of this issue). This insight is already incorporated in the rules that most charter schools in the US operate under (they cannot be selective in who they accept), but it is important to apply it to the way that the RtE Act will be implemented.

Our results and discussion point towards several avenues for future research on school choice. The first is to better estimate education production functions with a specific focus on the relationship between instructional time per subject and test scores, and on the role of the language of instruction (including positive and negative spillovers to other subjects, and heterogeneous impacts as a function of home characteristics). Second, the analysis in this paper (and in most of the school choice literature) has focused exclusively on the impacts of choice on test scores and learning outcomes, and has ignored welfare gains to households from enhanced choice and match quality. A natural extension therefore is to estimate a structural model of school choice using revealed preference of program take up, and estimate the welfare gains to households from introducing new schools into their feasible choice set by bringing their price down sharply through vouchers (Bresnahan and Gordon 1996, Carneiro et al. 2013).

Three further sets of research questions are first order in the Indian context. First, it would be important to replicate this experiment with the value of the voucher set equal to the perstudent spending in public schools to measure the extent to which the greater productivity of private schools can translate into better absolute learning outcomes. Second, while we find suggestive evidence on the positive effects of greater choice and competition, more conclusive evidence will require running similar experiments in urban India - where the greater population density allows for much more choice and competition between schools. Third, our estimates are based on a voucher experiment with two cohorts of students, and do not capture the long-term dynamic impacts of a school choice system. Doing so would require modeling (and measuring) school entry and exit, as well as the endogenous price and quality responses of private schools in response to a steady stream of public funding for students to attend private schools in (Nielson 2013 conducts such an exercise in Chile). Indian states are currently starting to implement the RtE Act, and there is much fertile ground for future research to better understand education markets in low-income settings and directly contribute to better education policy. 


\section{References:}

Abadzi, H. 2006. Efficient Learning for the Poor: Insights from the Frontier of Cognitive Neuroscience. Washington DC: The World Bank.

Abdulkadiroglu, A., J. Angrist, S. M. Dynarski, T. J. Kane, and P. A. Pathak. 2011. Accountability and Flexibility in Public Schools: Evidence from Boston's Charters and Pilots. Quarterly Journal of Economics 126:699-748.

Abdulkadiroglu, A., J. Angrist, and P. A. Pathak. 2014. The Elite Illusion: Achievement Effects at Boston and New York Exam Schools. Econometrica 82 (1):137-196.

Andrabi, T., J. Das, and A. Khwaja. 2012. Report Cards: The Impact of Providing School and Child Test-scores on Educational Markets: Harvard Kennedy School.

Andrabi, T., J. Das, A. Khwaja, and T. Zajonc. 2011. Do Value-Added Estimates Add Value? Accounting for Learning Dynamics. American Economic Journal: Applied Economics 3 (July):29-54.

Angrist, J., E. Bettinger, E. Bloom, E. King, and M. Kremer. 2002. Vouchers for Private Schooling in Colombia: Evidence from a Randomized Natural Experiment. American Economic Review 92 (5):1535-1558.

Angrist, J., E. Bettinger, and M. Kremer. 2006. Long-term Consequences of Secondary School Vouchers: Evidence from Secondary School Records in Colombia. American Economic Review 96 (3):847-862.

Angrist, J., and K. Lang. 2004. Does School Integration Generate Peer Effects? Evidence from Boston's Metco Program. American Economic Review 94 (5):1613-1634.

ASER. 2013. Annual Status of Education Report: Aser Centre.

Azam, M., A. Chin, and N. Prakash. 2013. The Returns to English Language Skills in India. Economic Development and Cultural Change.

Bajaj, V., and J. Yardley. 2011. Many of India's Poor Turn to Private Schools. The New York Times, 30 December 2011.

Baum, D. 2014. What Matters Most for Engaging the Private Sector in Education: A Framework Paper. Washington DC: World Bank.

Bloom, N., and J. Van Reenen. 2010. Why Do Management Practices Differ across Firms and Countries? Journal of Economic Perspectives 24 (1):203-224.

Bold, T., M. Kimenyi, G. Mwabu, and J. Sandefur. 2011. The High Return to Private Schooling in a Low-Income Country: Center for Global Development Working Paper 279.

Bresnahan, T., and R. Gordon, eds. 1996. The Economics of New Goods: National Bureau of Economic Research.

Carneiro, P., J. Das, and H. Reis. 2013. Parental Valuation of School Attributes in Developing Countries: Evidence from Pakistan: University College London.

Chakraborty, T., and S. Kapur. 2012. English Language Premium in a Globalizing Economy: Evidence from a Policy Experiment in India: Indian Institute of Technology, Kanpur.

Cullen, J. B., B. A. Jacob, and S. Levitt. 2006. The Effect of School Choice on Participants: Evidence from Randomized Lotteries. Econometrica 74 (5):1191-1230.

Das, J., S. Dercon, J. Habyarimana, P. Krishnan, K. Muralidharan, and V. Sundararaman. 2013. School Inputs, Household Substitution, and Test Scores. American Economic Journal: Applied Economics 5 (2):29-57.

Desai, S., A. Dubey, R. Vanneman, and R. Banerji. 2009. Private Schooling in India: A New Educational Landscape. In India Policy Forum, edited by S. Bery, B. Bosworth and A. Panagariya. New Delhi: Sage. 
Dobbie, W., and R. G. Fryer. 2011. Are High-Quality Schools Enough to Increase Achievement Among the Poor? Evidence from the Harlem Children's Zone. American Economic Journal: Applied Economics 3 (3):158-187.

Dongre, A. 2012. What is the Per Child Expenditure in Government Schools? In Accountability Initiative. New Delhi.

French, R. J., and G. Kingdon. 2010. The relative effectiveness of private and government schools in Rural India: Evidence from ASER data. London: Institute of Education.

Friedman, M. 1962. Capitalism and Freedom. Chicago: University of Chicago Press.

Goyal, S., and P. Pandey. 2009. How do Government and Private Schools Differ? Findings from two large Indian states: World Bank.

Grewal, D. 2008. Network Power: The Social Dynamics of Globalization: Yale University Press.

Hastings, J. S., and J. M. Weinstein. 2008. Information, School Choice, and Academic Achievement: Evidence from Two Experiments. Quarterly Journal of Economics.

Howell, W. G., and P. E. Peterson. 2002. The Education Gap: Vouchers and Urban Schools. Washington DC: Brookings Institution.

Howell, W. G., P. J. Wolf, D. E. Campbell, and P. E. Peterson. 2002. School vouchers and academic performance: results from three randomized field trials. Journal of Policy Analysis and Management 21 (2):191-217.

Hoxby, C. 2000. Does Competition Among Public Schools Benefit Students and Taxpayers? American Economic Review 90 (5):1209-1238.

Hoxby, C., S. Murarka, and J. Kang. 2009. How New York City's Charter Schools Affect Achievement.

Hsieh, C.-T., and M. Urquiola. 2006. The effects of generalized school choice on achievement and stratification: Evidence from Chile's school voucher program. Journal of Public Economics 90 (1477-1503).

Jain, T. 2014. Common Tongue: The Impact of Language on Educational Outcomes: Indian School of Business.

Kelkar, V. January 16, 2006. Let Every Parent be a Consumer. India Today, January 16, 2006.

Kling, J. R., J. B. Liebman, and L. F. Katz. 2007. Experimental Analysis of Neighborhood Effects. Econometrica 75 (1):83-119.

Kremer, M., K. Muralidharan, N. Chaudhury, F. H. Rogers, and J. Hammer. 2005. Teacher Absence in India: A Snapshot. Journal of the European Economic Association 3 (2-3):658-667.

Krueger, A., and P. Zhu. 2004. Another Look at the New York City School Voucher Experiment. American Behavioral Scientist 47 (5):658-698.

Lee, D. 2009. Training, Wages, and Sample Selection: Estimating Sharp Bounds on Treatment Effects. Review of Economic Studies 76 (3):1071-1102.

Lucas, A. M., and I. Mbiti. 2014. Effects of School Quality on Student Achievement: Discontinuity Evidence from Kenya. American Economic Journal: Applied Economics 6 (3):234-263.

Macleod, B. W., and M. Urquiola. 2012. Anti-Lemons: School Reputation, Relative Diversity, and Educational Quality: IZA Discussion Paper No. 6805.

Meganathan, R. 2011. Language Policy in education and the role of English in India: From library language to language of empowerment. In Dreams and Realities: Developing Countries and the English Language, edited by H. Coleman. London: British Council.

Munshi, K., and M. R. Rosenzweig. 2006. Traditional Institutions Meet the Modern World: Caste, Gender, and Schooling Choice in a Globalizing Economy. American Economic Review 96 (4):1225-1252.

Muralidharan, K., J. Das, A. Holla, and A. Mohpal. 2014. The Fiscal Costs of Weak Governance: Evidence from Teacher Absence in India. NBER Working Paper 20299. 
Muralidharan, K., and M. Kremer. 2008. Public and Private Schools in Rural India. In School Choice International, edited by P. Peterson and R. Chakrabarti. Cambridge: MIT.

Muralidharan, K., and V. Sundararaman. 2010. The Impact of Diagnostic Feedback to Teachers on Student Learning: Experimental Evidence from India. Economic Journal 120 (546):F187F203.

- 2011. Teacher Performance Pay: Experimental Evidence from India. Journal of Political Economy 119 (1):39-77.

- 2013. Contract Teachers: Experimental Evidence from India: NBER Working Paper 19440.

Muralidharan, K., and Y. Zieleniak. 2014. Chasing the Syllabus: Meauring Learning Trajectories in Developing Countries with Longitudinal Data and Item Response Theory: UC San Diego.

Nielson, C. 2013. Targeted Vouchers, Competition Among Schools, and the Academic Achievement of Poor Students: Yale.

Olken, B., J. Onishi, and S. Wong. 2012. Should Aid Reward Performance? Evidence from a Field Experiment on Health and Education in Indonesia: NBER Working Paper 17892.

Pop-Eleches, C., and M. Urquiola. 2013. Going to a Better School: Effects and Behavioral Responses. American Economic Review 103 (4):1289-1324.

Rangaraju, B., J. Tooley, and P. Dixon. 2012. The Private School Revolution in Bihar: Findings from a Survey in Patna Urban.

Rao, G. 2014. Familiarity Does Not Breed Contempt: Diversity, Discrimination, and Generosity in Delhi Schools: Harvard.

Rouse, C. E., and L. Barrow. 2009. School Vouchers and Student Achievement: Recent Evidence and Remaining Questions. Annual Review of Economics 1:17-42.

Sachar, R., R. Basant, S. Hamid, A. Majeed, T. K. Oomen, and A. Shariff. 2006. Social, Economic, and Educational Status of the Muslim Community in India. New Delhi: Government of India.

Shah, G. R. 2012. India Opens a Door to Private Education. The New York Times, 19 August 2012.

Shah, P. 2005. Equity in Education. Business Standard, July 13, 2005.

Shastry, K. 2012. Human Capital Response to Globalization: Education and Information Technology in India. Journal of Human Resources 47 (2):287-330.

Singh, A. 2014. The Private School Premium: Size and sources of the private school advantage in test scores in India: Oxford.

Srivastava, P. 2013. Low-fee Private Schooling: aggravating equity or mitigating disadvantage: Symposium Books.

Srivastava, P., and G. Walford, eds. 2007. Private Schooling in Less Economically Developed Countries: Asian and African Perspectives Oxford Studies in Comparative Education.

Tabarrok, A. 2013. Private Education in India: A Novel Test of Cream Skimming. Contemporary Economic Policy 31 (1):1-12.

Tooley, J. 2009. The Beautiful Tree: A Personal Journey into How the World's Poorest People are Educating Themselves. New Delhi: Penguin.

Tooley, J., and P. Dixon. 2007. Private Education for Low-Income Families: Results from a Global Reseach Project. In Private Schooling in Less Economically Developed Countries: Asian and African Perspectives, edited by P. Srivastava and G. Walford: Oxford Studies in Comparative Education.

Wolf, P. J., B. Kisida, B. Gutmann, M. Puma, N. Eissa, and L. Rizzo. 2013. School Vouchers and Student Outcomes: Experimental Evidence from Washington, DC. Journal of Policy Analysis and Management 32 (2):246-270.

Zhang, H. 2014. The Mirage of Elite Schools: Evidence from Lottery-based School Admissions in China: Chinese University of Hong Kong. 
Table 1: School and Teacher Characteristics

Total enrollment

Total working days

Pupil-teacher ratio

Drinking water available

Functional toilets

Separate functional toilets for girls

Functional electricity

Functional computers

Functional library

Functional radio

Observations

\begin{tabular}{ccc}
\hline \hline Private schools & Public schools & Difference \\
\hline$[1]$ & {$[2]$} & {$[3]$} \\
\hline 296.21 & 74.04 & $222.17^{\star \star \star}$ \\
229.81 & 218.66 & $11.15^{\star \star \star}$ \\
17.62 & 25.28 & $-7.67^{\star \star \star}$ \\
0.99 & 0.92 & $0.07^{\star \star \star}$ \\
0.86 & 0.68 & $0.18^{\star \star \star}$ \\
0.77 & 0.40 & $0.37^{\star \star \star}$ \\
0.88 & 0.61 & $0.28^{\star \star \star}$ \\
0.52 & 0.05 & $0.48^{\star \star \star}$ \\
0.80 & 0.97 & $-0.18^{\star \star \star}$ \\
0.13 & 0.81 & $-0.68^{\star \star \star}$ \\
289 & 346 &
\end{tabular}

\section{Male}

Age

Years of teaching

Completed at least college or masters

Teacher training completed

Come from the same village

Current gross salary per month (Rs.)

Observations

\begin{tabular}{ccc}
\hline \hline \multicolumn{3}{c}{ Panel B: Teacher Characteristics } \\
\hline \hline 0.24 & 0.46 & $-0.21^{\star \star \star}$ \\
27.58 & 40.00 & $-12.42^{\star \star \star}$ \\
5.14 & 14.96 & $-9.82^{\star \star \star}$ \\
0.69 & 0.88 & $-0.19^{\star \star \star}$ \\
0.34 & 0.99 & $-0.65^{\star \star \star}$ \\
0.44 & 0.13 & $0.32^{\star \star \star}$ \\
2606.66 & 14285.94 & $-11679.27^{\star * *}$ \\
2,000 & 1,358 & \\
& \\
\hline \hline
\end{tabular}

Annual cost per child (Rs./child)

1848.88

8390.00

$-6542^{\star \star \star}$

Observations

211

325

Notes:

${ }^{*} p<0.1 ; * * p<0.05 ; * * * p<0.01$. All standard errors are clustered at the school level. The sample for Panels A and B are restricted to schools and teachers in control villages across years 2008 through 2012. In cases of multiple observations per school or teacher across different years,

variable means are used (so each teacher/school is one observation). All expenditures are measured in Rupees per student per year, trimmed at the 1st and 99th percentiles to remove outliers. The actual number of observations for each regression may vary slightly within columns based on

the dependent variable. Estimates of annual cost per child in government schools come from government budget documents for 2010 . The

private school figures for Panel C are therefore limited to private schools in control villages in 2010. 


\section{Table 2: Teacher and School Effort}

\begin{tabular}{|c|c|c|c|}
\hline & \multicolumn{3}{|c|}{ Panel A: Measures of Classroom Activity } \\
\hline & Private schools & Public schools & Difference \\
\hline & [1] & [2] & [3] \\
\hline Class is engaged in active teaching & 0.51 & 0.34 & $0.17^{\star \star \star}$ \\
\hline A teacher is present in class & 0.97 & 0.92 & $0.048^{\star \star \star}$ \\
\hline Teacher is effective in teaching and maintaining discipline & 0.50 & 0.36 & $0.14^{\star \star \star}$ \\
\hline Teacher has complete control over class & 0.69 & 0.41 & $0.28^{\star \star \star}$ \\
\hline Teachers teaching mutliple classes at the same time & 0.24 & 0.79 & $-0.55^{\star \star \star}$ \\
\hline \multirow[t]{2}{*}{ Observations } & 2,738 & 2,784 & \\
\hline & \multicolumn{3}{|c|}{ Panel B: Measures of Teacher Activity } \\
\hline Teacher is Absent & 0.09 & 0.24 & $-0.15^{\star \star \star}$ \\
\hline Teacher is actively teaching & 0.50 & 0.35 & $0.15^{\star \star \star}$ \\
\hline Teacher is in school and not teaching & 0.01 & 0.03 & $-0.02^{\star \star \star}$ \\
\hline \multirow[t]{2}{*}{ Observations } & 6,577 & 5,552 & \\
\hline & \multicolumn{3}{|c|}{ Panel C: Measures of School Hygiene } \\
\hline Flies heavily present on premises of the school & 0.14 & 0.19 & $-0.05^{\star \star}$ \\
\hline Stagnant water present on premises of the school & 0.18 & 0.28 & $-0.10^{\star \star \star}$ \\
\hline Garbage dumped on premises of the school & 0.33 & 0.44 & $-0.11^{\star \star \star}$ \\
\hline Observations & 426 & 614 & \\
\hline \multicolumn{4}{|l|}{ Notes: } \\
\hline
\end{tabular}


Table 3: Household Inputs

\begin{tabular}{|c|c|c|c|c|c|c|c|}
\hline & \multicolumn{7}{|c|}{ Panel A: Student Time Diaries (Minutes per Day) } \\
\hline & Private schools & Public schools & Difference & $\begin{array}{l}\text { Applicants } \\
\text { offered } \\
\text { scholarship }\end{array}$ & $\begin{array}{l}\text { Applicants in } \\
\text { control villages }\end{array}$ & $\begin{array}{l}\text { Intention to } \\
\text { treat estimate }\end{array}$ & $\begin{array}{l}\text { Treatment on } \\
\text { the treated } \\
\text { estimate }\end{array}$ \\
\hline & {$[1]$} & [2] & [3] & [4] & [5] & [6] & [7] \\
\hline \multicolumn{8}{|l|}{ Activity: } \\
\hline Time spent in school & 423.53 & 380.25 & $43.28^{\star \star \star}$ & 409.34 & 383.38 & $25.96^{\star \star \star}$ & $46.93^{\star \star \star}$ \\
\hline Studying and doing homework at home & 75.99 & 52.72 & $23.27^{\star \star \star}$ & 59.83 & 56.86 & 2.97 & 5.38 \\
\hline Private tuition & 25.15 & 16.62 & $8.53^{\star \star \star}$ & 21.95 & 17.43 & 4.52 & 8.17 \\
\hline Bathing/toilet/getting ready & 55.11 & 61.7 & $-6.59^{\star \star \star}$ & 57.82 & 61.24 & -3.42 & -6.19 \\
\hline Time traveling to school & 23.5 & 20.92 & 2.58 & 23.51 & 21.43 & 2.08 & 3.75 \\
\hline Working (outside/inside the house) & 1.51 & 11.05 & $-9.54^{\star \star \star}$ & 5.46 & 9.36 & $-3.90^{*}$ & $-7.14^{*}$ \\
\hline Chores & 16.82 & 31.18 & $-14.36^{\star \star \star}$ & 21.62 & 34.45 & $-12.84^{\star \star \star}$ & $-23.51^{\star \star \star}$ \\
\hline Watching TV & 75.88 & 83.38 & $-7.50^{\star *}$ & 80.57 & 84.04 & -3.47 & -6.28 \\
\hline Playing with friends & 82.34 & 101.99 & $-19.65^{\star \star \star}$ & 100.88 & 99.73 & 1.15 & 2.08 \\
\hline Eating & 43.57 & 44.69 & -1.12 & 43.78 & 44.12 & -0.34 & -0.61 \\
\hline Free time & 53.38 & 64.38 & $-11.00^{\star \star \star}$ & 56.69 & 62.13 & -5.44 & -9.96 \\
\hline \multirow[t]{2}{*}{ Observations } & 652 & 1839 & & 885 & 1212 & & 2097 \\
\hline & \multicolumn{7}{|c|}{ Panel B: Household Student Expenditure (Rupees per Year) } \\
\hline \multicolumn{8}{|l|}{ Household expenditure on student: } \\
\hline School admissions & 140.58 & 14.95 & $125.63^{\star \star *}$ & 34.35 & 31.23 & 3.12 & 5.76 \\
\hline Uniforms & 416.68 & 200.41 & $216.27^{\star \star \star}$ & 171.14 & 237.07 & $-65.94^{\star \star \star}$ & $-121.77^{\star \star \star}$ \\
\hline Notebooks/textbooks & 554.46 & 228.57 & $325.89^{* * *}$ & 209.05 & 278.35 & $-69.29 * \star \star$ & $-127.40^{\star \star \star}$ \\
\hline Special events & 15.91 & 7.29 & $8.62^{\star \star \star}$ & 5.30 & 9.04 & $-3.74^{*}$ & $-6.93^{*}$ \\
\hline Transportation & 113.61 & 13.59 & $100.02^{\star \star \star}$ & 46.55 & 43.57 & 2.99 & 5.51 \\
\hline Private tuition & 71.07 & 32.51 & $38.56^{\star \star \star}$ & 34.80 & 39.55 & -4.75 & -8.75 \\
\hline Total expenditure & 2910.36 & 566.73 & $2343.64^{\star \star \star}$ & 774.94 & 892.69 & -117.75 & -215.95 \\
\hline Observations & 634 & 1815 & & 858 & 1182 & & 2040 \\
\hline \multicolumn{8}{|l|}{ Notes: } \\
\hline \multicolumn{8}{|c|}{$\begin{array}{l}{ }^{*} p<0.1 ;{ }^{*} p<0.05 ;{ }^{* *} p<0.01 \text {. All regressions include a constant and district fixed effects. All standard errors are clustered at the village level. In } \\
\text { all columns in Panels A, the sample is based on student time-use diaries from a normal, non-sick school day. The sample for columns [1] through } \\
\text { [3] is restricted to students and schools in control villages. The samples for columns [4] through [7] is applicants offered vouchers in treatment } \\
\text { villages and applicants not offered vouchers in control villages. Data for both panels come from the household surveys administered between } \\
2008 \text { and } 2012 \text {. The chores activity consists of preparing meals, caring for other children, and caring for the elderly. Total expenditure includes the } \\
\text { categories listed and all other school-related expenditures. The actual number of observations for each regression may vary slightly within } \\
\text { columns based on the dependent variable. }\end{array}$} \\
\hline
\end{tabular}


Table 4: Test Score Impacts

\begin{tabular}{|c|c|c|c|c|c|c|c|c|c|c|}
\hline & \multicolumn{10}{|c|}{ Panel A: Impact of Winning a Voucher ("Intention to Treat" Effects) } \\
\hline & \multicolumn{4}{|c|}{ Year 2 Assessments } & \multicolumn{6}{|c|}{ Year 4 Assessments } \\
\hline & $\begin{array}{l}\text { Telugu } \\
\text { score }\end{array}$ & Math score & $\begin{array}{l}\text { English } \\
\text { score }\end{array}$ & $\begin{array}{c}\text { Combined } \\
\text { across tests }\end{array}$ & $\begin{array}{l}\text { Telugu } \\
\text { score }\end{array}$ & Math score & $\begin{array}{l}\text { English } \\
\text { score }\end{array}$ & $\begin{array}{l}\text { Science and } \\
\text { social studies } \\
\text { (EVS) score }\end{array}$ & Hindi score & $\begin{array}{l}\text { Combined } \\
\text { across tests }\end{array}$ \\
\hline & [1] & [2] & [3] & [4] & [5] & [6] & [7] & [8] & [9] & [10] \\
\hline \multirow[t]{2}{*}{ Offered scholarship } & -0.079 & -0.053 & $0.185^{\star *}$ & 0.016 & -0.017 & -0.031 & $0.116^{*}$ & 0.083 & $0.545^{\star \star *}$ & $0.133^{\star \star *}$ \\
\hline & $(0.055)$ & $(0.065)$ & $(0.079)$ & $(0.061)$ & $(0.051)$ & $(0.052)$ & $(0.070)$ & $(0.060)$ & $(0.068)$ & $(0.045)$ \\
\hline Total observations & 4,620 & 4,620 & 4,525 & 13,765 & 4,385 & 4,385 & 4,217 & 4,243 & 1,696 & 18,926 \\
\hline Treatment observations & 1,778 & 1,778 & 1,738 & 5,294 & 1,674 & 1,675 & 1,607 & 1,628 & 867 & 7,451 \\
\hline \multirow[t]{3}{*}{ Control observations } & 2,842 & 2,842 & 2,787 & 8,471 & 2,711 & 2,710 & 2,610 & 2,615 & 829 & 11,475 \\
\hline & \multicolumn{10}{|c|}{$\begin{array}{l}\text { Panel B: Impact of Attending a Private School ("Treatment on the Treated" Effects, Using Lottery-based Voucher } \\
\text { Award as an Instrumental Variable) }\end{array}$} \\
\hline & \multicolumn{4}{|c|}{ Year 2 assessments } & \multicolumn{6}{|c|}{ Year 4 assessments } \\
\hline \multirow[t]{2}{*}{ Scholarship recipient in private school } & -0.141 & -0.094 & $0.328^{\star *}$ & 0.029 & -0.031 & -0.055 & $0.204^{\star}$ & 0.146 & $0.923^{\star \star \star}$ & $0.233^{\star \star \star}$ \\
\hline & $(0.097)$ & $(0.116)$ & $(0.138)$ & $(0.108)$ & $(0.090)$ & $(0.092)$ & $(0.122)$ & $(0.106)$ & $(0.102)$ & $(0.078)$ \\
\hline Total observations & 4,620 & 4,620 & 4,525 & 13,765 & 4,385 & 4,385 & 4,217 & 4,243 & 1,696 & 18,926 \\
\hline Scholarship recipients & 997 & 997 & 982 & 5,294 & 945 & 946 & 911 & 920 & 510 & 7,451 \\
\hline Non-recipients & 3,623 & 3,623 & 3,543 & 8,471 & 3,440 & 3,439 & 3,306 & 3,323 & 1,186 & 11,475 \\
\hline First-stage F-stat & 368 & 368 & 366 & 369 & 361 & 363 & 382 & 374 & 407 & 391 \\
\hline
\end{tabular}

\section{Notes:}

${ }^{*} p<0.1 ;{ }^{* *} p<0.05 ; * \star * p<0.01$. All regressions control for baseline normalized test scores and include a constant and district fixed effects. All standard errors are clustered at the village level. All test scores are normalized across relative to the distribution of public school students in control villages by subject and grade. Telugu, math, English and EVS (science and social studies) test scores are from written end of year tests; Hindi test scores are from an individual assessment administered to a representative sample of students. Combined scores are obtained by running a pooled regression across all test scores in each year, with Hindi test score observations weighted up by the inverse of the sampling probability within a given group of a student being selected to take the test from the universe of students. Controls include all the variables shown and defined in Table

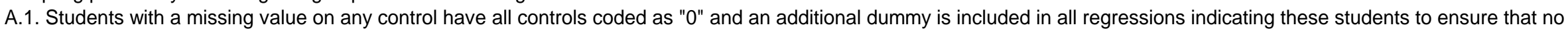
observations are lost due to missing data on any individual control. Results are unchanged without controlling for the socioeconomic variables in Table A.1. The only result whose significance changes without socioeconomic controls (that improve precision) is the 4-year impact on English that moves from a p-value of 0.098 (with controls) to a pvalue of 0.113 (without controls). 
Table 5: School Time Use

\begin{tabular}{|c|c|c|c|}
\hline & \multicolumn{3}{|c|}{ Instructional Time by Subject (Minutes per Week) } \\
\hline & Private schools & Public schools & Difference \\
\hline & [1] & [2] & [3] \\
\hline Telugu & $\begin{array}{c}307.72 \\
(6.36)\end{array}$ & $\begin{array}{c}511.52 \\
(3.60)\end{array}$ & $\begin{array}{c}-203.81^{\star \star \star} \\
(6.99)\end{array}$ \\
\hline Math & $\begin{array}{c}339.75 \\
(7.50)\end{array}$ & $\begin{array}{c}500.69 \\
(3.36)\end{array}$ & $\begin{array}{c}-160.94^{\star \star \star} \\
(8.63)\end{array}$ \\
\hline English & $\begin{array}{c}322.68 \\
(7.96)\end{array}$ & $\begin{array}{c}235.52 \\
(5.39)\end{array}$ & $\begin{array}{c}87.17^{\star \star \star} \\
(9.69)\end{array}$ \\
\hline Social studies & $\begin{array}{c}239.21 \\
(6.29)\end{array}$ & $\begin{array}{c}173.24 \\
(6.89)\end{array}$ & $\begin{array}{c}65.96^{\star \star \star} \\
(9.84)\end{array}$ \\
\hline Science & $\begin{array}{c}205.52 \\
(9.09)\end{array}$ & $\begin{array}{c}104.58 \\
(5.78)\end{array}$ & $\begin{array}{c}100.94^{\star \star \star} \\
(9.44)\end{array}$ \\
\hline Hindi & $\begin{array}{c}215.78 \\
(6.08)\end{array}$ & $\begin{array}{c}0.01 \\
(0.89)\end{array}$ & $\begin{array}{c}215.77^{\star \star \star} \\
(6.41)\end{array}$ \\
\hline Moral science & $\begin{array}{l}16.85 \\
(4.82)\end{array}$ & $\begin{array}{l}20.11 \\
(3.20)\end{array}$ & $\begin{array}{l}-3.26 \\
(5.56)\end{array}$ \\
\hline Computer use & $\begin{array}{c}46.7 \\
(6.50)\end{array}$ & $\begin{array}{c}0.51 \\
(1.02)\end{array}$ & $\begin{array}{c}46.19 \star \star \star \\
(6.80)\end{array}$ \\
\hline Other & $\begin{array}{l}311.66 \\
(14.55)\end{array}$ & $\begin{array}{c}250.29 \\
(6.70)\end{array}$ & $\begin{array}{c}61.37^{\star \star \star} \\
(16.20)\end{array}$ \\
\hline Total instructional time & $\begin{array}{c}2005.87 \\
(13.73)\end{array}$ & $\begin{array}{c}1796.47 \\
(6.86)\end{array}$ & $\begin{array}{c}209.4^{\star \star *} \\
(14.46)\end{array}$ \\
\hline Break & $\begin{array}{c}461 \\
(9.14)\end{array}$ & $\begin{array}{c}473.18 \\
(3.05)\end{array}$ & $\begin{array}{l}-12.18 \\
(10.58)\end{array}$ \\
\hline Total school time & $\begin{array}{c}2466.87 \\
(17.46)\end{array}$ & $\begin{array}{c}2269.65 \\
(8.25)\end{array}$ & $\begin{array}{c}197.22 * \star * \\
(19.79)\end{array}$ \\
\hline Observations & 325 & 200 & \\
\hline
\end{tabular}

Notes:

${ }^{*} p<0.1 ;{ }^{* *} p<0.05 ;{ }^{* *} p<0.01$. All regressions include a constant and district fixed effects. All standard errors are clustered at the village level. The sample for this table is restricted to schools in control villages. All numbers in minutes per week. Other includes sports/PE, arts and crafts, and study hall. 
Table 6: Robustness to Attrition (ITT Estimates)

\begin{tabular}{|c|c|c|c|c|c|c|c|c|c|c|}
\hline & \multicolumn{10}{|c|}{ Panel A: Inverse Probability Re-weighting } \\
\hline & \multicolumn{4}{|c|}{ Year 2 Assessments } & \multicolumn{6}{|c|}{ Year 4 Assessments } \\
\hline & $\begin{array}{l}\text { Telugu } \\
\text { score }\end{array}$ & Math score & $\begin{array}{l}\text { English } \\
\text { score }\end{array}$ & $\begin{array}{c}\text { Combined } \\
\text { across tests }\end{array}$ & $\begin{array}{l}\text { Telugu } \\
\text { score }\end{array}$ & Math score & $\begin{array}{l}\text { English } \\
\text { score }\end{array}$ & $\begin{array}{l}\text { Science and } \\
\text { social studies } \\
\text { (EVS) score }\end{array}$ & Hindi score & $\begin{array}{c}\text { Combined } \\
\text { across tests }\end{array}$ \\
\hline & {$[1]$} & [2] & [3] & [4] & [5] & [6] & [7] & [8] & [9] & [10] \\
\hline Offered scholarship & $\begin{array}{l}-0.081 \\
(0.055)\end{array}$ & $\begin{array}{l}-0.054 \\
(0.065)\end{array}$ & $\begin{array}{l}0.183^{\star \star} \\
(0.079)\end{array}$ & $\begin{array}{l}0.014 \\
(0.061)\end{array}$ & $\begin{array}{l}-0.018 \\
(0.051)\end{array}$ & $\begin{array}{l}-0.031 \\
(0.052)\end{array}$ & $\begin{array}{l}0.115 \\
(0.070)\end{array}$ & $\begin{array}{l}0.082 \\
(0.060)\end{array}$ & $\begin{array}{c}0.542^{\star \star \star} \\
(0.068)\end{array}$ & $\begin{array}{c}0.137^{\star \star \star} \\
(0.045)\end{array}$ \\
\hline Total observations & 4,620 & 4,620 & 4,525 & 13,765 & 4,385 & 4,385 & 4,217 & 4,243 & 1,696 & 18,926 \\
\hline Treatment observations & 1,778 & 1,778 & 1,738 & 5294 & 1,674 & 1,675 & 1,607 & 1,628 & 867 & 7451 \\
\hline \multirow[t]{4}{*}{ Control observations } & 2,842 & 2,842 & 2,787 & 8471 & 2,711 & 2,710 & 2,610 & 2,615 & 829 & 11475 \\
\hline & \multicolumn{10}{|c|}{ Panel B: Lee Bounds } \\
\hline & \multicolumn{4}{|c|}{ Year 2 assessments } & \multicolumn{6}{|c|}{ Year 4 assessments } \\
\hline & {$[1]$} & {$[2]$} & {$[3]$} & {$[4]$} & {$[5]$} & [6] & [7] & [8] & {$[9]$} & {$[10]$} \\
\hline Lower bound estimate & $\begin{array}{l}-0.148 \\
(0.031)\end{array}$ & $\begin{array}{l}-0.142 \\
(0.031)\end{array}$ & $\begin{array}{l}0.076 \\
(0.039)\end{array}$ & $\begin{array}{l}-0.079 \\
(0.020)\end{array}$ & $\begin{array}{l}-0.076 \\
(0.036)\end{array}$ & $\begin{array}{l}-0.112 \\
(0.035)\end{array}$ & $\begin{array}{l}0.001 \\
(0.046)\end{array}$ & $\begin{array}{l}-0.010 \\
(0.040)\end{array}$ & $\begin{array}{l}0.493 \\
(0.063)\end{array}$ & $\begin{array}{c}0.052 \\
(0.020)\end{array}$ \\
\hline Upper bound estimate & $\begin{array}{c}0.028 \\
(0.030)\end{array}$ & $\begin{array}{l}0.041 \\
(0.030)\end{array}$ & $\begin{array}{l}0.262 \\
(0.039)\end{array}$ & $\begin{array}{l}0.110 \\
(0.019)\end{array}$ & $\begin{array}{l}0.059 \\
(0.034)\end{array}$ & $\begin{array}{l}0.045 \\
(0.033)\end{array}$ & $\begin{array}{l}0.199 \\
(0.042)\end{array}$ & $\begin{array}{l}0.200 \\
(0.041)\end{array}$ & $\begin{array}{l}0.591 \\
(0.062)\end{array}$ & $\begin{array}{c}0.220 \\
(0.019)\end{array}$ \\
\hline Confidence interval low & -0.208 & -0.202 & -0.001 & -0.118 & -0.145 & -0.180 & -0.090 & -0.089 & 0.368 & 0.014 \\
\hline Confidence interval high & 0.087 & 0.099 & 0.337 & 0.147 & 0.125 & 0.109 & 0.281 & 0.280 & 0.712 & 0.256 \\
\hline
\end{tabular}

Notes:

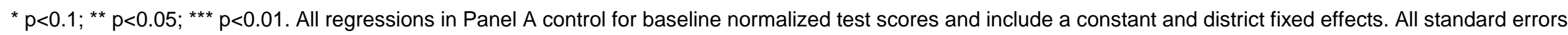
are clustered at the village level. Test scores are as defined in Table 4. 
Table 7: Spillovers (ITT Estimates)

\begin{tabular}{|c|c|c|c|c|c|c|c|c|c|}
\hline & \multicolumn{4}{|c|}{ Year 2 Assessments } & \multicolumn{5}{|c|}{ Year 4 Assessments } \\
\hline & $\begin{array}{l}\text { Telugu } \\
\text { score }\end{array}$ & Math score & $\begin{array}{l}\text { English } \\
\text { score }\end{array}$ & $\begin{array}{c}\text { Combined } \\
\text { across tests }\end{array}$ & $\begin{array}{l}\text { Telugu } \\
\text { score }\end{array}$ & Math score & $\begin{array}{l}\text { English } \\
\text { score }\end{array}$ & $\begin{array}{l}\text { Science and } \\
\text { social studies } \\
\text { (EVS) score }\end{array}$ & $\begin{array}{c}\text { Combined } \\
\text { across tests }\end{array}$ \\
\hline & \multicolumn{9}{|c|}{ Panel A: Comparing the Within-Village to Across-Village Controls } \\
\hline & 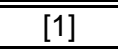 & {$[2]$} &  & 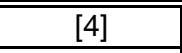 & [5] & [6] & [7] & [8] &  \\
\hline Lottery loser in treatment village & $\begin{array}{l}0.010 \\
(0.060)\end{array}$ & $\begin{array}{c}0.011 \\
(0.071)\end{array}$ & $\begin{array}{c}0.041 \\
(0.090)\end{array}$ & $\begin{array}{l}0.020 \\
(0.069)\end{array}$ & $\begin{array}{c}0.011 \\
(0.058)\end{array}$ & $\begin{array}{l}-0.002 \\
(0.057)\end{array}$ & $\begin{array}{l}-0.048 \\
(0.067)\end{array}$ & $\begin{array}{l}0.093 \\
(0.071)\end{array}$ & $\begin{array}{l}0.013 \\
(0.055)\end{array}$ \\
\hline Total observations & 3,784 & 3,784 & 3,705 & 11,273 & 3,606 & 3,605 & 3,472 & 3,488 & 14,171 \\
\hline Treatment observations & 942 & 942 & 918 & 2,802 & 895 & 895 & 862 & 873 & 3,525 \\
\hline \multirow[t]{2}{*}{ Control observations } & 2,842 & 2,842 & 2,787 & 8,471 & 2,711 & 2,710 & 2,610 & 2,615 & 10,646 \\
\hline & \multicolumn{9}{|c|}{ Panel B: Impact on Non-applicants from Public Schools } \\
\hline Treatment village & $\begin{array}{l}-0.022 \\
(0.071)\end{array}$ & $\begin{array}{l}0.056 \\
(0.066)\end{array}$ & $\begin{array}{c}0.129 \\
(0.089)\end{array}$ & $\begin{array}{c}0.054 \\
(0.067)\end{array}$ & $\begin{array}{c}0.064 \\
(0.061)\end{array}$ & $\begin{array}{c}0.012 \\
(0.067)\end{array}$ & $\begin{array}{c}0.039 \\
(0.069)\end{array}$ & $\begin{array}{l}-0.004 \\
(0.071)\end{array}$ & $\begin{array}{c}0.028 \\
(0.055)\end{array}$ \\
\hline Total observations & 1,030 & 1,030 & 1,008 & 3,068 & 1,173 & 1,174 & 1,145 & 1,149 & 4,641 \\
\hline Treatment observations & 490 & 490 & 476 & 1,456 & 555 & 555 & 541 & 542 & 2,193 \\
\hline \multirow[t]{2}{*}{ Control observations } & 540 & 540 & 532 & 1,612 & 618 & 619 & 604 & 607 & 2,448 \\
\hline & \multicolumn{9}{|c|}{ Panel C: Impact on Non-scholarship Students from Private Schools } \\
\hline Treatment village & $\begin{array}{c}0.067 \\
(0.060)\end{array}$ & $\begin{array}{l}0.028 \\
(0.073)\end{array}$ & $\begin{array}{l}-0.112 \\
(0.073)\end{array}$ & $\begin{array}{l}-0.000 \\
(0.060)\end{array}$ & $\begin{array}{c}0.043 \\
(0.061)\end{array}$ & $\begin{array}{c}0.038 \\
(0.059)\end{array}$ & $\begin{array}{l}-0.019 \\
(0.098)\end{array}$ & $\begin{array}{l}0.029 \\
(0.073)\end{array}$ & $\begin{array}{l}0.024 \\
(0.057)\end{array}$ \\
\hline Total observations & 1,386 & 1,386 & 1,346 & 4,118 & 1,522 & 1,521 & 1,463 & 1,468 & 5,974 \\
\hline Treatment observations & 721 & 721 & 708 & 2,150 & 802 & 802 & 777 & 773 & 3,154 \\
\hline Control observations & 665 & 665 & 638 & 1,968 & 720 & 719 & 686 & 695 & 2,820 \\
\hline
\end{tabular}

Notes:

${ }^{*} \mathrm{p}<0.1 ;{ }^{* \star} \mathrm{p}<0.05 ;{ }^{* *} \mathrm{p}<0.01$. All regressions control for baseline normalized test scores and include a constant and district fixed effects. All standard errors are clustered at the village level. Test scores are as defined in Table 4. 
Table 8: Heterogeneous Test Score Impacts by Student Characteristics (ITT Estimates)

\begin{tabular}{|c|c|c|c|c|c|c|c|c|c|c|}
\hline & \multicolumn{4}{|c|}{ Year 2 Assessments } & \multicolumn{6}{|c|}{ Year 4 Assessments } \\
\hline & $\begin{array}{l}\text { Telugu } \\
\text { score }\end{array}$ & Math score & $\begin{array}{l}\text { English } \\
\text { score }\end{array}$ & $\begin{array}{l}\text { Combined } \\
\text { across tests }\end{array}$ & $\begin{array}{l}\text { Telugu } \\
\text { score }\end{array}$ & Math score & $\begin{array}{l}\text { English } \\
\text { score }\end{array}$ & $\begin{array}{l}\text { Science and } \\
\text { social studies } \\
\text { (EVS) score }\end{array}$ & Hindi score & $\begin{array}{l}\text { Combined } \\
\text { across tests }\end{array}$ \\
\hline & [1] & [2] & [3] & {$[4]$} & [5] & {$[6]$} & [7] & [8] & [9] & [10] \\
\hline \multicolumn{11}{|c|}{ Offered scholarship * covariate } \\
\hline \multirow[t]{2}{*}{ Baseline test score } & -0.056 & -0.054 & -0.074 & -0.062 & 0.004 & 0.000 & -0.022 & -0.022 & $-0.107^{*}$ & -0.031 \\
\hline & $(0.042)$ & $(0.043)$ & $(0.052)$ & $(0.041)$ & $(0.037)$ & $(0.037)$ & $(0.047)$ & $(0.043)$ & $(0.061)$ & $(0.033)$ \\
\hline \multirow[t]{2}{*}{ Female student } & 0.013 & 0.069 & 0.117 & 0.065 & 0.010 & -0.037 & 0.013 & 0.017 & $0.173^{*}$ & 0.035 \\
\hline & $(0.055)$ & $(0.054)$ & $(0.076)$ & $(0.054)$ & $(0.064)$ & $(0.064)$ & $(0.071)$ & $(0.071)$ & $(0.101)$ & $(0.053)$ \\
\hline \multirow[t]{2}{*}{ Scheduled caste student } & -0.012 & 0.042 & -0.025 & 0.001 & 0.029 & 0.099 & 0.006 & 0.056 & -0.110 & 0.013 \\
\hline & $(0.069)$ & $(0.066)$ & $(0.082)$ & $(0.066)$ & $(0.070)$ & $(0.070)$ & $(0.090)$ & $(0.083)$ & $(0.124)$ & $(0.064)$ \\
\hline \multirow[t]{2}{*}{ Parents literate indicator } & 0.043 & -0.022 & -0.011 & 0.003 & -0.031 & -0.006 & 0.132 & $-0.138^{*}$ & $-0.240^{\star *}$ & -0.059 \\
\hline & $(0.065)$ & $(0.060)$ & $(0.089)$ & $(0.062)$ & $(0.068)$ & $(0.070)$ & $(0.120)$ & $(0.077)$ & $(0.121)$ & $(0.064)$ \\
\hline \multirow[t]{2}{*}{ Parents laborers indicator } & -0.006 & 0.042 & 0.018 & 0.016 & 0.050 & $0.144^{\star \star}$ & 0.148 & 0.019 & -0.125 & 0.052 \\
\hline & $(0.069)$ & $(0.069)$ & $(0.083)$ & $(0.066)$ & $(0.069)$ & $(0.071)$ & $(0.102)$ & $(0.081)$ & $(0.118)$ & $(0.065)$ \\
\hline \multirow[t]{2}{*}{ Household asset index } & 0.014 & 0.031 & -0.018 & 0.010 & -0.028 & -0.001 & 0.009 & -0.019 & 0.018 & -0.002 \\
\hline & $(0.031)$ & $(0.033)$ & $(0.045)$ & $(0.032)$ & $(0.033)$ & $(0.031)$ & $(0.038)$ & $(0.035)$ & $(0.063)$ & $(0.030)$ \\
\hline \multirow[t]{2}{*}{ Muslim student } & $0.232^{\star *}$ & $0.258^{*}$ & $0.404^{\star \star}$ & $0.298^{\star \star}$ & $0.364^{\star \star \star}$ & $0.290^{\star \star}$ & 0.151 & $0.288^{\star \star}$ & 0.113 & $0.262^{\star \star \star}$ \\
\hline & $(0.116)$ & $(0.137)$ & $(0.177)$ & $(0.126)$ & $(0.112)$ & $(0.128)$ & $(0.147)$ & $(0.140)$ & $(0.173)$ & $(0.098)$ \\
\hline \multirow[t]{2}{*}{ Christian student } & -0.099 & -0.085 & -0.208 & -0.130 & -0.154 & $-0.232^{\star \star}$ & -0.113 & -0.109 & -0.198 & -0.174 \\
\hline & $(0.122)$ & $(0.126)$ & $(0.157)$ & $(0.122)$ & $(0.130)$ & $(0.111)$ & $(0.121)$ & $(0.159)$ & $(0.255)$ & $(0.113)$ \\
\hline \multirow[t]{2}{*}{ Older cohort at baseline } & 0.020 & -0.062 & 0.107 & 0.019 & -0.045 & -0.055 & 0.101 & -0.051 & 0.120 & 0.015 \\
\hline & $(0.072)$ & $(0.083)$ & $(0.089)$ & $(0.071)$ & $(0.082)$ & $(0.087)$ & $(0.116)$ & $(0.097)$ & $(0.107)$ & $(0.069)$ \\
\hline Observations & 4,620 & 4,620 & 4,525 & 13,765 & 4,385 & 4,385 & 4,217 & 4,243 & 1,696 & 18,926 \\
\hline
\end{tabular}

Notes:

${ }^{*} p<0.1 ;{ }^{*} p<0.05 ;{ }^{* \star *} p<0.01$. Each cell reports the coefficient from a separate regression that also includes controls for the characteristic in question, an indicator for whether a student was offered a voucher, and the student's normalized baseline test scores. All regressions include a constant and district fixed effects and standard errors are clustered at the village level. All test scores are as defined in Table 4, and indicators for assets and literacy are as defined in Table A.1. The actual number of observations for each regression may vary slightly within columns based on the dependent variable. 
Table 9: Heterogeneous Test Score Impacts (by Medium of Instruction - IV Estimates)

Panel A: Treatment on the Treated Effects by Medium of Instruction (all Four Instruments)

\begin{tabular}{|c|c|c|c|c|c|c|c|c|c|c|}
\hline \multicolumn{4}{|c|}{ Year 2 Assessments } & \multicolumn{7}{|c|}{ Year 4 Assessments } \\
\hline Telugu score & Math score & English score & $\begin{array}{l}\text { Combined } \\
\text { across tests }\end{array}$ & Telugu score & Math score & English score & $\begin{array}{l}\text { Science and } \\
\text { social studies } \\
\text { (EVS) score }\end{array}$ & Hindi score & $\begin{array}{l}\text { Combined across } \\
\text { tests }\end{array}$ & $\begin{array}{l}\text { Combined across non- } \\
\text { language subjects (math \& } \\
\text { science/social studies) }\end{array}$ \\
\hline [1] & [2] & [3] & [4] & [5] & [6] & [7] & [8] & [9] & [10] & [11] \\
\hline-0.078 & -0.010 & $0.683^{\star \star \star}$ & 0.198 & -0.272 & -0.349 & $0.677^{\star \star}$ & -0.197 & $1.379^{\star \star \star}$ & 0.223 & -0.274 \\
\hline$(0.164)$ & $(0.175)$ & $(0.232)$ & $(0.174)$ & $(0.244)$ & $(0.248)$ & $(0.339)$ & $(0.298)$ & $(0.250)$ & $(0.204)$ & $(0.255)$ \\
\hline-0.033 & 0.062 & 0.408 & 0.143 & 0.259 & 0.255 & 0.043 & $0.746^{\star \star}$ & $1.384^{\star \star \star}$ & $0.532^{\star \star \star}$ & $0.496^{*}$ \\
\hline$(0.168)$ & $(0.197)$ & $(0.285)$ & $(0.202)$ & $(0.245)$ & $(0.254)$ & $(0.171)$ & $(0.313)$ & $(0.230)$ & $(0.181)$ & $(0.275)$ \\
\hline 4,291 & 4,291 & 4,209 & 12,791 & 4,070 & 4,070 & 3,922 & 3,935 & 1,576 & 17,573 & 8,005 \\
\hline 33.2 & 33.2 & 32.9 & 33.2 & 12.1 & 12.2 & 12.4 & 12.1 & 11.2 & 12.6 & 12.2 \\
\hline 38.3 & 38.3 & 39.4 & 38.7 & 21.5 & 21.5 & 22.1 & 20.5 & 20.6 & 22.2 & 21.1 \\
\hline 0.80 & 0.72 & 0.33 & 0.78 & 0.15 & 0.13 & 0.09 & 0.06 & 0.99 & 0.29 & 0.07 \\
\hline \multicolumn{11}{|c|}{ Panel B: Treatment on the Treated Effects by Medium of Instruction (only Interactions as Instruments) } \\
\hline \multicolumn{4}{|c|}{ Year 2 Assessments } & \multicolumn{7}{|c|}{ Year 4 Assessments } \\
\hline [1] & [2] & [3] & [4] & [5] & [6] & [7] & [8] & [9] & [10] & [11] \\
\hline-0.242 & -0.173 & $0.595^{\star \star}$ & 0.060 & -0.523 & -0.591 & $0.978^{\star \star}$ & -0.104 & $1.426^{\star \star \star}$ & 0.213 & -0.352 \\
\hline$(0.231)$ & $(0.239)$ & $(0.289)$ & $(0.232)$ & $(0.385)$ & $(0.381)$ & $(0.460)$ & $(0.384)$ & $(0.365)$ & $(0.285)$ & $(0.360)$ \\
\hline 0.201 & 0.294 & 0.535 & 0.339 & 0.513 & 0.501 & -0.274 & 0.651 & $1.337^{\star \star \star}$ & $0.542^{\star}$ & 0.575 \\
\hline$(0.252)$ & $(0.260)$ & $(0.417)$ & $(0.291)$ & $(0.450)$ & $(0.458)$ & $(0.376)$ & $(0.446)$ & $(0.328)$ & $(0.320)$ & $(0.442)$ \\
\hline 4,291 & 4,291 & 4,209 & 12,791 & 4,070 & 4,070 & 3,922 & 3,935 & 1,576 & 17,573 & 8,005 \\
\hline 38.4 & 38.4 & 38.2 & 18.3 & 17.7 & 17.8 & 18.1 & 17.6 & 16.2 & 38.4 & 17.8 \\
\hline 30.6 & 30.6 & 31.1 & 25.1 & 25.4 & 25.4 & 25.2 & 25.1 & 20.2 & 30.8 & 25.4 \\
\hline 0.3 & 0.2 & 0.9 & 0.5 & 0.2 & 0.2 & 0.1 & 0.3 & 0.9 & 0.5 & 0.2 \\
\hline
\end{tabular}

${ }^{*} \mathrm{p}<0.1$; $* \star \mathrm{p}<0.05 ;{ }^{* \star \star} \mathrm{p}<0.01$. In Panel A, we instrument for the medium of instruction of private school attended using the medium of instruction of the nearest private school and the interaction of receiving a voucher and the medium of instruction of the nearest private school. First stage regressions are shown in Table A.8. In Panel B, we instrument for the medium of instruction of private school attended using only the interaction of receiving a voucher and the medium of instruction of the nearest private school, and we control for the the closest private school being English medium and for the closest private school being Telugu medium. In both panels, we also control for mother's and father's

education, scheduled caste status, and a household asset index as defined in Table A.1. All regressions control for baseline normalized test scores. The results in this table do not include district fixed effects, because one of the districts has very few English-medium schools. All standard errors are clustered at the village level. The sample is around 7\% smaller than that in Table 4 (due to missing location data). All test scores are defined as in Table 4. 


\section{Table 10: Heterogeneous Test Score Impacts by Market Competition (ITT Estimates)}

\begin{tabular}{|c|c|c|c|c|c|c|c|c|c|c|}
\hline & \multicolumn{4}{|c|}{ Year 2 Assessments } & \multicolumn{6}{|c|}{ Year 4 Assessments } \\
\hline & $\begin{array}{l}\text { Telugu } \\
\text { score }\end{array}$ & Math score & $\begin{array}{l}\text { English } \\
\text { score }\end{array}$ & $\begin{array}{c}\text { Combined } \\
\text { across tests }\end{array}$ & $\begin{array}{l}\text { Telugu } \\
\text { score }\end{array}$ & Math score & $\begin{array}{l}\text { English } \\
\text { score }\end{array}$ & $\begin{array}{l}\text { Science and } \\
\text { social studies } \\
\text { (EVS) score }\end{array}$ & Hindi score & $\begin{array}{l}\text { Combined } \\
\text { across tests }\end{array}$ \\
\hline & {$[1]$} & [2] & [3] & {$[4]$} & {$[5]$} & {$[6]$} & [7] & {$[8]$} & {$[9]$} & {$[10]$} \\
\hline Number of private schools within $1 \mathrm{~km}$ (linear) & $\begin{array}{c}0.024 \\
(0.022)\end{array}$ & $\begin{array}{c}0.015 \\
(0.028)\end{array}$ & $\begin{array}{c}0.019 \\
(0.034)\end{array}$ & $\begin{array}{c}0.020 \\
(0.025)\end{array}$ & $\begin{array}{c}0.027 \\
(0.024)\end{array}$ & $\begin{array}{l}-0.001 \\
(0.027)\end{array}$ & $\begin{array}{l}-0.021 \\
(0.032)\end{array}$ & $\begin{array}{l}-0.001 \\
(0.030)\end{array}$ & $\begin{array}{l}-0.007 \\
(0.031)\end{array}$ & $\begin{array}{l}-0.003 \\
(0.021)\end{array}$ \\
\hline 3 or more schools within $1 \mathrm{~km}$ (top $25 \%$ ) & $\begin{array}{c}0.042 \\
(0.110)\end{array}$ & $\begin{array}{l}-0.065 \\
(0.126)\end{array}$ & $\begin{array}{c}-0.127 \\
(0.150)\end{array}$ & $\begin{array}{l}-0.048 \\
(0.118)\end{array}$ & $\begin{array}{c}0.046 \\
(0.102)\end{array}$ & $\begin{array}{l}-0.051 \\
(0.104)\end{array}$ & $\begin{array}{c}-0.067 \\
(0.158)\end{array}$ & $\begin{array}{l}-0.084 \\
(0.115)\end{array}$ & $\begin{array}{l}-0.108 \\
(0.139)\end{array}$ & $\begin{array}{l}-0.065 \\
(0.085)\end{array}$ \\
\hline 5 or more schools within $1 \mathrm{~km}$ (top $10 \%$ ) & $\begin{array}{c}0.192 \\
(0.117)\end{array}$ & $\begin{array}{c}0.251^{\star} \\
(0.137)\end{array}$ & $\begin{array}{c}0.270 \\
(0.199)\end{array}$ & $\begin{array}{c}0.238^{\star} \\
(0.134)\end{array}$ & $\begin{array}{l}0.230 * \\
(0.129)\end{array}$ & $\begin{array}{c}0.125 \\
(0.151)\end{array}$ & $\begin{array}{l}-0.151 \\
(0.177)\end{array}$ & $\begin{array}{c}0.178 \\
(0.160)\end{array}$ & $\begin{array}{l}-0.004 \\
(0.166)\end{array}$ & $\begin{array}{c}0.061 \\
(0.123)\end{array}$ \\
\hline 6 or more schools within $1 \mathrm{~km}$ (Top 5\%) & $\begin{array}{c}0.183 \\
(0.136)\end{array}$ & $\begin{array}{c}0.295 \\
(0.198)\end{array}$ & $\begin{array}{c}0.452 \\
(0.314)\end{array}$ & $\begin{array}{c}0.309 \\
(0.205)\end{array}$ & $\begin{array}{c}0.480^{\star \star \star} \\
(0.125)\end{array}$ & $\begin{array}{c}0.435^{\star \star \star} \\
(0.138)\end{array}$ & $\begin{array}{l}0.208^{\star \star} \\
(0.099)\end{array}$ & $\begin{array}{c}0.470 \star \star \star \\
(0.142)\end{array}$ & $\begin{array}{l}-0.099 \\
(0.228)\end{array}$ & $\begin{array}{l}0.290^{\star \star} \\
(0.116)\end{array}$ \\
\hline Observations & 4,612 & 4,612 & 4,518 & 13,742 & 4,378 & 4,378 & 4,215 & 4,237 & 1,689 & 18,897 \\
\hline
\end{tabular}

Notes:

${ }^{\star} p<0.1 ;{ }^{* \star} p<0.05 ;{ }^{* \star} p<0.01$. Each cell reports the coefficient from a separate regression that also includes controls for whether a student was offered a voucher and the student's normalized baseline test scores. All regressions include a constant district fixed effects and standard errors are clustered at the village level. All test scores are defined as in Table 4. 
Figure 1: Design of AP School Choice Program

Panel A: Treatment Villages
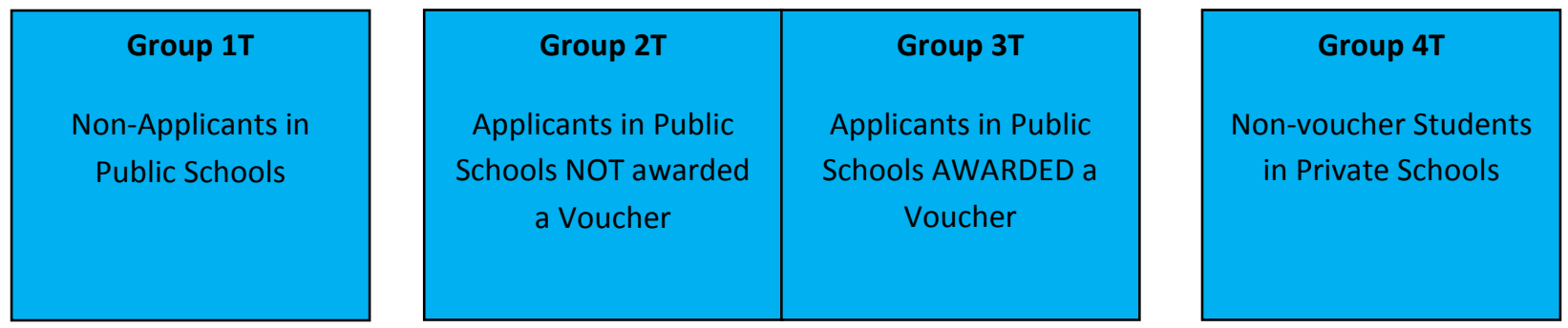

Panel B: Control Villages
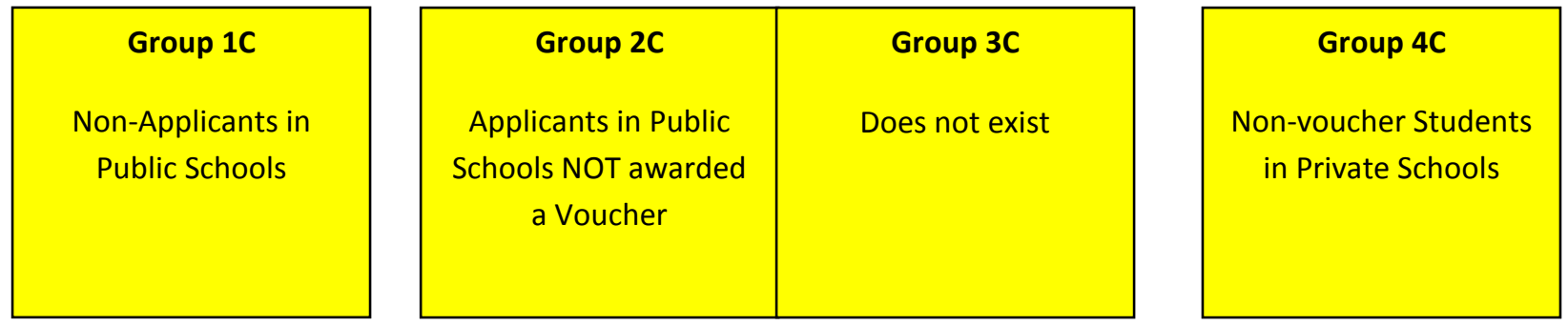

Figure 2: Design of AP School Choice Program with Student Counts

Treatment Villages

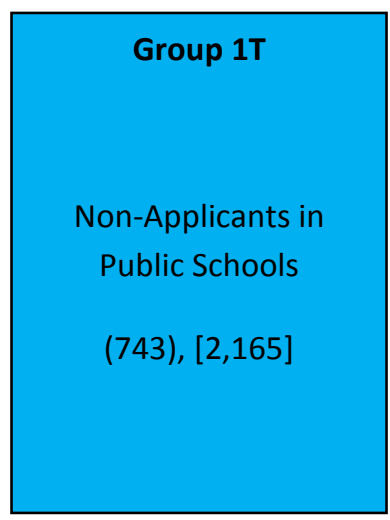

\begin{tabular}{|c|c|c|}
\hline Group 2T & Group $\mathbf{3}_{\boldsymbol{A}} \mathbf{T}$ & Group $\mathbf{3}_{\boldsymbol{B}} \mathbf{T}$ \\
Applicants in & Applicants in & Applicants in \\
Public & Public & Public \\
Schools NOT & Schools & Schools \\
awarded a & AWARDED & AWARDED \\
Voucher & but DID NOT & and \\
& ACCEPT a & ACCEPTED a \\
[1,117] & Voucher & Voucher \\
& [770; 975] & {$[1,210 ; 1,005]$} \\
\hline
\end{tabular}

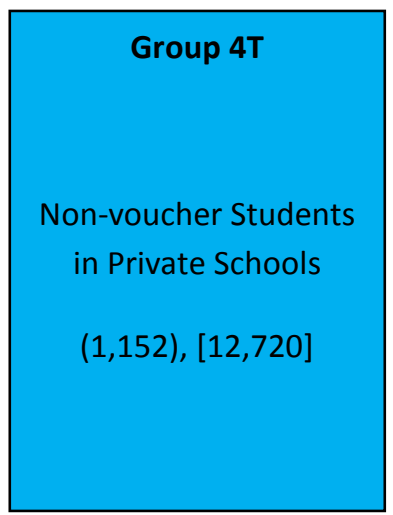

\section{Control Villages}
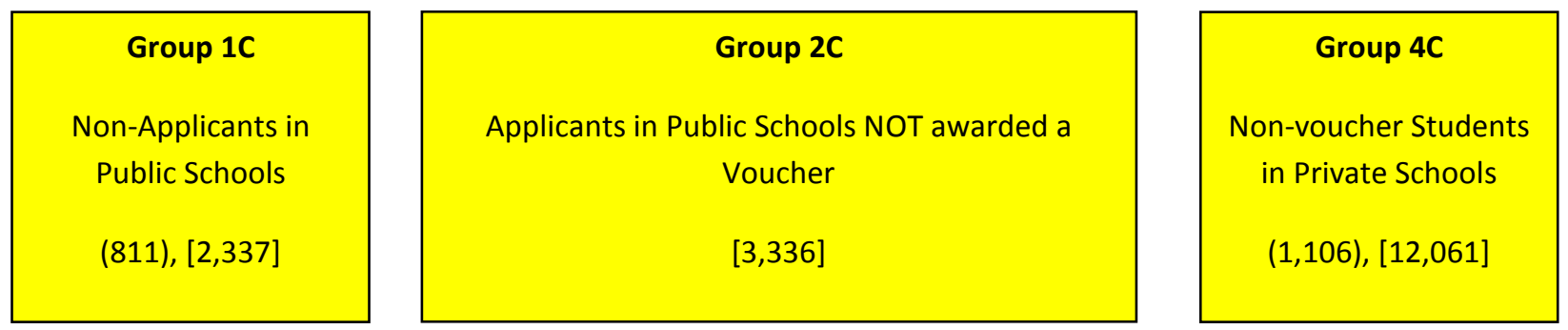

Notes: All of groups 2T, 3T, and 2C were sampled for tests of learning outcomes after two and four years of the project. For other groups, numbers in parentheses are the sample size that was tracked (with the total population in brackets). The two numbers under group $3_{\mathrm{B}} \mathrm{T}$ represent those who first accepted and started in a private school (1210) and those who were still in a private school at the end of 4 years $(1,005)$. Conversely in group $3_{\mathrm{A}} \mathrm{T}, 770$ initially rejected the offer, while 975 were no longer availing the voucher at the end of 4 year 


\section{Appendix Tables: A.1 - A.10}

Table A.1: Baseline Test Scores and Socio-Economic Characteristics

\begin{tabular}{lcccc}
\hline \hline & $\begin{array}{c}\text { Private } \\
\text { schools }\end{array}$ & Public schools & Difference & $\begin{array}{c}\text { Difference with } \\
\text { village fixed } \\
\text { effects }\end{array}$ \\
\cline { 2 - 5 } Normalized baseline Telugu score & {$[1]$} & {$[2]$} & {$[3]$} & {$[4]$} \\
Normalized baseline math score & 0.639 & 0.004 & $0.635^{\star \star \star}$ & $0.677^{\star \star \star}$ \\
Both parents have completed at least primary school & 0.661 & 0.015 & $0.646^{\star \star \star}$ & $0.678^{\star \star \star}$ \\
At least one parent has completed grade 10 & 0.558 & 0.285 & $0.273^{\star \star \star}$ & $0.308^{\star \star \star}$ \\
Scheduled caste & 0.689 & 0.394 & $0.295^{\star \star \star}$ & $0.325^{\star \star \star}$ \\
Household asset index & 0.128 & 0.329 & $-0.201^{\star \star \star}$ & $-0.193^{\star \star \star}$ \\
Annual school fees paid (Rs./month) & 3.846 & 3.193 & $0.653^{\star \star \star}$ & $0.646^{\star \star \star}$ \\
Observations & 1041.54 & 40.08 & $1001.27^{\star \star \star}$ & $1001.46^{\star \star \star}$
\end{tabular}

\section{Notes:}

${ }^{*} p<0.1 ;{ }^{* \star} p<0.05 ;{ }^{* \star *} p<0.01$. All standard errors are clustered at the school level. The sample for this table is restricted to students in control villages at the baseline (2008). Telugu and math scores are normalized relative to the distribution of public school students in control villages by subject and grade. The household asset index reported is a sum of five household indicators, including whether a household owns its own home, has a non-mud house, has at least one covered room, has working water facilities, and has a toilet available. 
Table A.2: Voucher Take-up (Application and Acceptance)

\begin{tabular}{|c|c|c|}
\hline & \multicolumn{2}{|c|}{ Correlates of Application and Acceptance } \\
\hline & Applied $==1$ & $\begin{array}{c}\text { Accepted==1 } \\
\text { (conditional on winning) }\end{array}$ \\
\hline & [1] & [2] \\
\hline \multirow[t]{2}{*}{ Normalized baseline Telugu score } & -0.006 & 0.013 \\
\hline & $(0.009)$ & $(0.014)$ \\
\hline \multirow[t]{2}{*}{ Scheduled caste } & 0.005 & -0.036 \\
\hline & $(0.013)$ & $(0.022)$ \\
\hline \multirow[t]{2}{*}{ Muslim } & -0.014 & -0.027 \\
\hline & $(0.023)$ & $(0.047)$ \\
\hline \multirow[t]{2}{*}{ Female } & -0.001 & 0.000 \\
\hline & $(0.009)$ & $(0.022)$ \\
\hline \multirow[t]{2}{*}{ Both parents literate } & 0.022 & -0.004 \\
\hline & $(0.014)$ & $(0.020)$ \\
\hline \multirow[t]{2}{*}{ Household asset index } & 0.008 & 0.017 \\
\hline & $(0.007)$ & $(0.011)$ \\
\hline \multirow[t]{2}{*}{ Older sibling in government school } & $-0.022^{*}$ & $-0.062^{\star \star \star}$ \\
\hline & $(0.013)$ & $(0.019)$ \\
\hline \multirow[t]{2}{*}{ Private school exists within 0.5 kilometers } & $0.065^{\star \star \star}$ & $0.078^{\star \star}$ \\
\hline & $(0.022)$ & $(0.036)$ \\
\hline \multirow[t]{2}{*}{ Older cohort } & $-0.070 * \star \star$ & $-0.084^{\star \star \star}$ \\
\hline & $(0.015)$ & $(0.022)$ \\
\hline Observations & 7,987 & 1,980 \\
\hline
\end{tabular}

\section{Notes:}

${ }^{*} p<0.1 ;{ }^{* \star} p<0.05 ;{ }^{* \star} p<0.01$. Each cell reports the coefficient from a separate binary regression that also includes a constant and district fixed effects. All standard errors are clustered at the village level. Column 1 compares applicants to non-applicants, and includes all students who were eligible to apply for the voucher. Column 2 compares those who accepted the voucher to those who did not (conditional on winning), and includes all students who were awarded a voucher. The actual number of observations for each regression may vary slightly within columns based on the dependent variable. The household asset index is as defined in Table A.1. 
Table A.3: Validity of Design

\begin{tabular}{|c|c|c|c|c|c|c|}
\hline & \multicolumn{6}{|c|}{ Panel A: Treatment and Control Students } \\
\hline & $\begin{array}{c}\text { Lottery } \\
\text { winners } \\
\text { [treatment } \\
\text { villages] }\end{array}$ & $\begin{array}{l}\text { Lottery losers } \\
\text { [treatment } \\
\text { villages] }\end{array}$ & $\begin{array}{l}\text { P-value for } \\
\text { difference }\end{array}$ & $\begin{array}{l}\text { Lottery } \\
\text { winners } \\
\text { [treatment } \\
\text { villages] }\end{array}$ & $\begin{array}{l}\text { Lottery losers } \\
\text { [control } \\
\text { villages] }\end{array}$ & $\begin{array}{l}\text { P-value for } \\
\text { difference }\end{array}$ \\
\hline & {$[1]$} & [2] & [3] & {$[4]$} & {$[5]$} & {$[6]$} \\
\hline Normalized baseline Telugu score & 0.03 & 0.05 & 0.46 & 0.03 & -0.04 & 0.30 \\
\hline Normalized baseline math score & 0.01 & 0.00 & 0.75 & 0.01 & -0.02 & 0.74 \\
\hline Both parents have completed at least primary school & 0.29 & 0.28 & 0.44 & 0.31 & 0.28 & 0.62 \\
\hline At least one parent has completed grade 10 & 0.34 & 0.34 & 0.88 & 0.34 & 0.36 & 0.16 \\
\hline Scheduled caste & 0.34 & 0.33 & 0.27 & 0.34 & 0.32 & 0.45 \\
\hline Household asset index & 3.17 & 3.15 & 0.49 & 3.17 & 3.19 & 0.71 \\
\hline \multirow[t]{3}{*}{ Observations } & 1,980 & 1,119 & & 1,980 & 3,334 & \\
\hline & \multicolumn{6}{|c|}{ Panel B: Students for Spillover Analysis } \\
\hline & $\begin{array}{c}\text { Non- } \\
\text { applicants in } \\
\text { treatment } \\
\text { villages }\end{array}$ & $\begin{array}{c}\text { Non- } \\
\text { applicants in } \\
\text { control } \\
\text { villages }\end{array}$ & $\begin{array}{l}\text { P-value for } \\
\text { difference }\end{array}$ & $\begin{array}{l}\text { Students } \\
\text { initially in } \\
\text { private } \\
\text { schools in } \\
\text { treatment } \\
\text { villages }\end{array}$ & $\begin{array}{l}\text { Students } \\
\text { initially in } \\
\text { private } \\
\text { schools in } \\
\text { control } \\
\text { villages }\end{array}$ & $\begin{array}{l}\text { P-value for } \\
\text { difference }\end{array}$ \\
\hline Normalized baseline Telugu score & -0.02 & 0.04 & 0.58 & 0.55 & 0.66 & 0.16 \\
\hline Normalized baseline math score & -0.04 & 0.06 & 0.41 & 0.72 & 0.59 & 0.17 \\
\hline Both parents have completed at least primary school & 0.28 & 0.27 & 0.92 & 0.52 & 0.55 & 0.45 \\
\hline At least one parent has completed grade 10 & 0.29 & 0.32 & 0.39 & 0.50 & 0.54 & 0.20 \\
\hline Scheduled caste & 0.34 & 0.31 & 0.43 & 0.12 & 0.13 & 0.57 \\
\hline Household asset index & 3.08 & 3.18 & 0.28 & 3.84 & 3.85 & 0.91 \\
\hline Sample observations & 734 & 809 & & 1,151 & 1,104 & \\
\hline Total observations & 2,816 & 2,756 & & 12,720 & 12,061 & \\
\hline
\end{tabular}

Notes:

All variables are as defined in Table A.1. All standard errors are clustered at the school level. Note that standard errors in the test score analysis are clustered (more conservatively) at the village level. None of the baseline differences reported above are statistically significant with clustering at either the school or village level. 
Table A.4: Attrition

\begin{tabular}{|c|c|c|c|c|c|c|c|c|c|c|c|}
\hline \multicolumn{12}{|c|}{ Panel A: Voucher Winners and Losers } \\
\hline \multicolumn{6}{|c|}{ Year 2 Assessments } & \multicolumn{6}{|c|}{ Year 4 Assessments } \\
\hline $\begin{array}{l}\text { Lottery } \\
\text { winners } \\
\text { [treatment } \\
\text { villages] }\end{array}$ & $\begin{array}{l}\text { Lottery losers } \\
\text { [treatment } \\
\text { villages] }\end{array}$ & $\begin{array}{l}\text { P-value for } \\
\text { difference }\end{array}$ & $\begin{array}{l}\text { Lottery } \\
\text { winners } \\
\text { [treatment } \\
\text { villages] }\end{array}$ & $\begin{array}{l}\text { Lottery losers } \\
\text { [control } \\
\text { villages] }\end{array}$ & $\begin{array}{l}\text { P-value for } \\
\text { difference }\end{array}$ & $\begin{array}{l}\text { Lottery } \\
\text { winners } \\
\text { [treatment } \\
\text { villages] }\end{array}$ & $\begin{array}{l}\text { Lottery losers } \\
\text { [treatment } \\
\text { villages] }\end{array}$ & $\begin{array}{l}\text { P-value for } \\
\text { difference }\end{array}$ & $\begin{array}{l}\text { Lottery } \\
\text { winners } \\
\text { [treatment } \\
\text { villages] }\end{array}$ & $\begin{array}{l}\text { Lottery losers } \\
\text { [control } \\
\text { villages] }\end{array}$ & $\begin{array}{l}\text { P-value for } \\
\text { difference }\end{array}$ \\
\hline [1] & [2] & [3] & [4] & [5] & [6] & [7] & [8] & [9] & {$[10]$} & [11] & [12] \\
\hline 0.90 & 0.84 & $0.00^{\star * \star}$ & 0.90 & 0.85 & $0.01^{\star \star}$ & 0.85 & 0.80 & $0.00^{\star \star \star}$ & 0.85 & 0.81 & $0.08^{*}$ \\
\hline 0.05 & 0.13 & 0.41 & 0.04 & 0.09 & 0.71 & 0.03 & 0.14 & 0.17 & 0.02 & 0.10 & 0.46 \\
\hline 0.06 & 0.03 & 0.83 & 0.06 & 0.10 & 0.86 & 0.05 & 0.01 & 0.72 & 0.05 & 0.10 & 0.78 \\
\hline 0.29 & 0.25 & 0.46 & 0.29 & 0.25 & 0.40 & 0.28 & 0.24 & 0.22 & 0.28 & 0.30 & 0.59 \\
\hline 0.33 & 0.32 & 0.81 & 0.33 & 0.34 & 0.81 & 0.33 & 0.29 & 0.27 & 0.33 & 0.38 & 0.23 \\
\hline 0.38 & 0.33 & 0.41 & 0.39 & 0.32 & 0.23 & 0.38 & 0.41 & 0.46 & 0.38 & 0.34 & 0.41 \\
\hline 3.15 & 3.02 & 0.18 & 3.15 & 3.08 & 0.66 & 3.15 & 3.10 & 0.48 & 3.15 & 3.21 & 0.71 \\
\hline 1,980 & 1,117 & & 1,980 & 3,336 & & 1,980 & 1,117 & & 1,980 & 3,338 & \\
\hline \multicolumn{12}{|c|}{ Panel B: Students for Spillover Analysis } \\
\hline \multicolumn{6}{|c|}{ Year 2 Assessments } & \multicolumn{6}{|c|}{ Year 4 Assessments } \\
\hline $\begin{array}{l}\text { Non- } \\
\text { applicants in } \\
\text { treatment } \\
\text { villages }\end{array}$ & $\begin{array}{l}\text { Non- } \\
\text { applicants in } \\
\text { control } \\
\text { villages }\end{array}$ & $\begin{array}{l}\text { P-value for } \\
\text { difference }\end{array}$ & $\begin{array}{l}\text { Students } \\
\text { initially in } \\
\text { private } \\
\text { schools in } \\
\text { treatment } \\
\text { villages }\end{array}$ & $\begin{array}{l}\text { Students } \\
\text { initially in } \\
\text { private } \\
\text { schools in } \\
\text { control } \\
\text { villages }\end{array}$ & $\begin{array}{l}\text { P-value for } \\
\text { difference }\end{array}$ & $\begin{array}{c}\text { Non- } \\
\text { applicants in } \\
\text { treatment } \\
\text { villages }\end{array}$ & $\begin{array}{l}\text { Non- } \\
\text { applicants in } \\
\text { control } \\
\text { villages }\end{array}$ & $\begin{array}{l}\text { P-value for } \\
\text { difference }\end{array}$ & $\begin{array}{c}\text { Students } \\
\text { initially in } \\
\text { private } \\
\text { schools in } \\
\text { treatment } \\
\text { villages }\end{array}$ & $\begin{array}{l}\text { Students } \\
\text { initially in } \\
\text { private } \\
\text { schools in } \\
\text { control } \\
\text { villages }\end{array}$ & $\begin{array}{l}\text { P-value for } \\
\text { difference }\end{array}$ \\
\hline 0.66 & 0.67 & 0.83 & 0.62 & 0.60 & 0.39 & 0.75 & 0.76 & 0.63 & 0.70 & 0.65 & 0.18 \\
\hline-0.03 & 0.07 & 0.52 & 0.58 & 0.72 & 0.15 & -0.07 & -0.02 & 0.81 & 0.51 & 0.75 & $.03^{\star *}$ \\
\hline-0.03 & 0.11 & 0.43 & 0.76 & 0.69 & 0.60 & -0.01 & 0.10 & 0.58 & 0.75 & 0.72 & 0.87 \\
\hline 0.26 & 0.25 & 0.86 & 0.57 & 0.61 & 0.33 & 0.18 & 0.22 & 0.51 & 0.57 & 0.63 & 0.25 \\
\hline 0.27 & 0.29 & 0.73 & 0.51 & 0.55 & 0.34 & 0.25 & 0.28 & 0.71 & 0.52 & 0.55 & 0.49 \\
\hline 0.38 & 0.28 & 0.10 & 0.14 & 0.13 & 0.81 & 0.35 & 0.29 & 0.41 & 0.16 & 0.15 & 0.79 \\
\hline 3.13 & 3.29 & 0.21 & 3.88 & 3.90 & 0.78 & 3.13 & 3.21 & 0.52 & 3.94 & 3.94 & 1.00 \\
\hline 743 & 811 & & 1,149 & 1,109 & & 743 & 811 & & 1,152 & 1,106 & \\
\hline
\end{tabular}

Characteristics

Present during the test

\section{Comparison of attritors}

Normalized baseline Telugu score

Normalized baseline math score

Both parents have completed at least primary schoo

At least one parent has completed grade 10

Scheduled caste

Household asset index

Observations

$743 \quad 811$

1,109

Notes:

All variables are as defined in Table A.1. All standard errors are clustered at the village level (the same unit of analysis in Table 4) 
Table A.5: Hindi Test Score Impacts by Question Type

\begin{tabular}{|c|c|c|c|c|c|}
\hline & \multicolumn{5}{|c|}{$\begin{array}{l}\text { Panel A: Impact of Winning a Voucher } \\
\text { ("Intention to Treat" Effects) }\end{array}$} \\
\hline & \multicolumn{5}{|c|}{ Student Score (Fraction Correct) by Question Type } \\
\hline & Letters & Words & Sentences & Paragraph & Advanced \\
\hline & [1] & [2] & [3] & [4] & [5] \\
\hline Offered voucher & $\begin{array}{c}0.234^{\star \star \star} \\
(0.028)\end{array}$ & $\begin{array}{l}0.171^{\star \star \star} \\
(0.026)\end{array}$ & $\begin{array}{c}0.122^{\star * *} \\
(0.023)\end{array}$ & $\begin{array}{c}0.121^{\star \star *} \\
(0.022)\end{array}$ & $\begin{array}{c}0.025^{\star \star \star} \\
(0.009)\end{array}$ \\
\hline Mean in control & 0.23 & 0.13 & 0.08 & 0.08 & 0.02 \\
\hline Total observations & 1,696 & 1,696 & 1,696 & 1,696 & 1,696 \\
\hline No. of obs. (voucher recipients) & 867 & 867 & 867 & 867 & 867 \\
\hline \multirow[t]{2}{*}{ No. of obs. (voucher non-recipients) } & 829 & 829 & 829 & 829 & 829 \\
\hline & \multicolumn{5}{|c|}{$\begin{array}{l}\text { Panel B: Impact of Attending a Private School } \\
\text { ("Treatment on the Treated" Effects, Using Lottery-based } \\
\text { Voucher Award as an Insturmental Variable) }\end{array}$} \\
\hline $\begin{array}{l}\text { Attended a private school (using voucher as an } \\
\text { instrument) }\end{array}$ & $\begin{array}{c}0.396^{\star \star \star} \\
(0.044)\end{array}$ & $\begin{array}{c}0.289 \star \star \star \\
(0.040)\end{array}$ & $\begin{array}{c}0.206^{\star \star \star} \\
(0.036)\end{array}$ & $\begin{array}{c}0.204^{\star \star \star} \\
(0.036)\end{array}$ & $\begin{array}{c}0.043^{\star \star \star} \\
(0.015)\end{array}$ \\
\hline Total observations & 1,696 & 1,696 & 1,696 & 1,696 & 1,696 \\
\hline No. of obs. (voucher acceptors) & 510 & 510 & 510 & 510 & 510 \\
\hline No. of obs. (voucher non-recipients and non-acceptors) & 1,186 & 1,186 & 1,186 & 1,186 & 1,186 \\
\hline
\end{tabular}

Notes:

All regressions include a constant and district fixed effects. All standard errors are clustered at the village level. The Hindi test scores are based on the ASER measurement tool used by Pratham to measure basic literacy, and were administered individually to a random sample of voucher winning and losing students in June 2012. Panel B instruments for private school attendance using the lottery-based offer of a voucher. 
Table A.6: Spillover Effects as a Function of Number of Voucher Students Received by each Private School

Instrumental Variable Estimate of the Impact of the Number of Voucher Students who Join a School on the Students who Started out in the Same Private School

\begin{tabular}{|c|c|c|c|c|c|c|}
\hline \multicolumn{3}{|c|}{ Year 2 Assessments } & \multicolumn{4}{|c|}{ Year 4 Assessments } \\
\hline Telugu score & Math score & English score & Telugu score & Math score & English score & $\begin{array}{l}\text { Science and } \\
\text { social studies } \\
\text { score }\end{array}$ \\
\hline [1] & [2] & [3] & [4] & [5] & [6] & [7] \\
\hline 0.011 & -0.004 & $-0.024^{*}$ & 0.017 & 0.009 & 0.028 & 0.001 \\
\hline$(0.012)$ & $(0.015)$ & $(0.013)$ & $(0.012)$ & $(0.014)$ & $(0.023)$ & $(0.015)$ \\
\hline 1,385 & 1,385 & 1,345 & 1,519 & 1,518 & 1,461 & 1,465 \\
\hline 48.6 & 48.6 & 47.1 & 64.2 & 64.2 & 80.6 & 64.5 \\
\hline
\end{tabular}

Observations

First-stage F-stat

48.6

48.6

64.2

64.2

80.6

64.5

Notes:

${ }^{*} \mathrm{p}<0.1 ;{ }^{* *} \mathrm{p}<0.05 ;{ }^{* *} \mathrm{p}<0.01$. All regressions control for baseline normalized test scores and include a constant and district fixed effects. All standard errors are clustered at the village level. All test scores are as defined in Table 4 . The number of voucher students a school received is instrumented by the interaction between potential exposure to voucher students (defined as the number of applicants for whom the given school is the nearest private school) and the fraction of those applicants who were offered the voucher (zero in all control villages). 
Table A.7: Spillover Effects as a Function of Number of Voucher Students (First-stage)

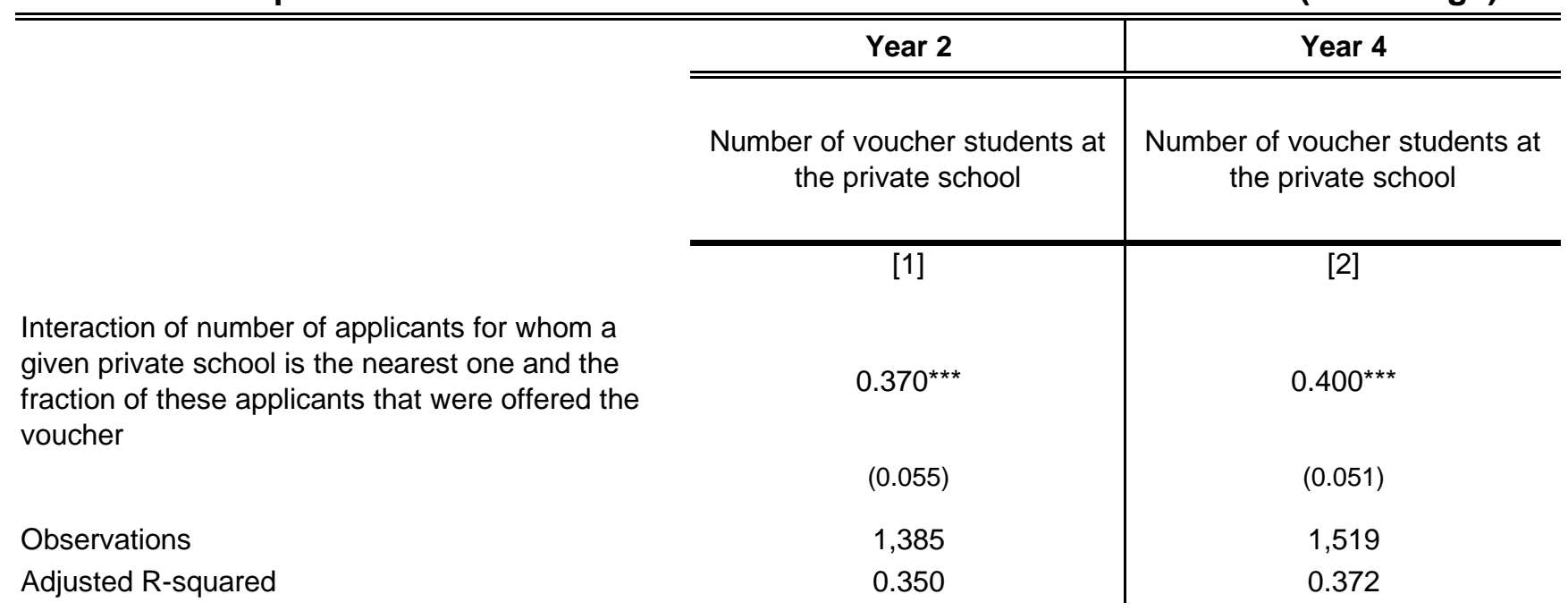

\section{Notes:}

${ }^{*} p<0.1 ;{ }^{* \star} p<0.05 ;{ }^{* \star} p<0.01$. All regressions control for baseline normalized test scores and include a constant and district fixed effects. All standard errors are clustered at the village level. The unit of observation is a student who started out in a private school, and the endogenous right-hand side variable of interest in Table A.6 is the number of voucher-winning students each of these students was exposed to. This table presents the first-stage of the instrumental variable regression used in Table A.6. 
Table A.8: Test Score Impacts by Medium of Instruction (First-stage)

\begin{tabular}{|c|c|c|c|c|}
\hline & \multicolumn{2}{|c|}{ Year 2} & \multicolumn{2}{|c|}{ Year 4} \\
\hline & $\begin{array}{l}\text { Student attends } \\
\text { private English } \\
\text { medium school }\end{array}$ & $\begin{array}{l}\text { Student attends } \\
\text { private Telugu } \\
\text { medium school }\end{array}$ & $\begin{array}{l}\text { Student attends } \\
\text { private English } \\
\text { medium school }\end{array}$ & $\begin{array}{c}\text { Student attends } \\
\text { private Telugu } \\
\text { medium school }\end{array}$ \\
\hline & [1] & [2] & [3] & [4] \\
\hline \multicolumn{5}{|l|}{ Instruments: } \\
\hline \multirow[t]{2}{*}{$\begin{array}{l}\text { Closest private school is English } \\
\text { medium }\end{array}$} & $0.064^{\star \star \star}$ & $-0.086^{\star \star \star}$ & 0.019 & $-0.040^{*}$ \\
\hline & $(0.020)$ & $(0.023)$ & $(0.024)$ & $(0.022)$ \\
\hline $\begin{array}{l}\text { Closest private school is Telugu } \\
\text { medium }\end{array}$ & (omitted) & (omitted) & (omitted) & (omitted) \\
\hline \multirow[t]{2}{*}{$\begin{array}{l}\text { Offered scholarship * closest } \\
\text { private school is English medium }\end{array}$} & $0.363^{\star * *}$ & $0.097^{\star \star \star}$ & $0.253^{\star \star \star}$ & $0.141^{\star \star \star}$ \\
\hline & $(0.040)$ & $(0.029)$ & $(0.045)$ & $(0.038)$ \\
\hline \multirow[t]{2}{*}{$\begin{array}{l}\text { Offered scholarship * closest } \\
\text { private school is Telugu medium }\end{array}$} & $0.085^{\star \star \star}$ & $0.387^{* \star *}$ & $0.070 * \star$ & $0.312^{\star * *}$ \\
\hline & $(0.028)$ & $(0.049)$ & $(0.031)$ & $(0.049)$ \\
\hline \multicolumn{5}{|l|}{ Controls: } \\
\hline \multirow[t]{2}{*}{ Normalized baseline test score } & $-0.018^{* *}$ & 0.001 & -0.007 & 0.006 \\
\hline & $(0.008)$ & $(0.009)$ & $(0.008)$ & $(0.009)$ \\
\hline \multirow[t]{2}{*}{$\begin{array}{l}\text { Both parents have completed at } \\
\text { least primary school }\end{array}$} & 0.033 & $-0.029 \star \star$ & $0.086^{\star * *}$ & -0.025 \\
\hline & $(0.016)$ & $(0.013)$ & $(0.019)$ & $(0.016)$ \\
\hline \multirow[t]{2}{*}{$\begin{array}{l}\text { At least one parent has completed } \\
\text { grade } 10\end{array}$} & $0.042^{\star \star \star}$ & $-0.022^{*}$ & $0.068^{\star \star \star}$ & $-0.034^{\star \star}$ \\
\hline & $(0.014)$ & $(0.012)$ & $(0.017)$ & $(0.013)$ \\
\hline \multirow[t]{2}{*}{ Scheduled caste } & $-0.043^{\star \star \star}$ & $-0.035^{\star *}$ & $-0.060^{* * *}$ & $-0.038^{\star * *}$ \\
\hline & $(0.014)$ & $(0.016)$ & $(0.015)$ & $(0.014)$ \\
\hline \multirow[t]{2}{*}{ Household asset index } & $0.016^{\star \star}$ & 0.007 & $0.020 * \star$ & $0.011^{*}$ \\
\hline & $(0.007)$ & $(0.006)$ & $(0.008)$ & $(0.007)$ \\
\hline \multirow[t]{2}{*}{ Constant } & -0.017 & $0.118^{\star \star \star}$ & $0.012^{\star * *}$ & $0.090^{\star \star *}$ \\
\hline & $(0.024)$ & $(0.029)$ & $(0.029)$ & $(0.024)$ \\
\hline Observations & 4,291 & 4,291 & 4,070 & 4,070 \\
\hline Adjusted R-squared & 0.176 & 0.230 & 0.107 & 0.132 \\
\hline
\end{tabular}

Notes:

${ }^{*} p<0.1 ;{ }^{* \star} p<0.05 ;{ }^{* \star} p<0.01$. All regressions control for baseline normalized test scores and standard errors are clustered at the village level. The sample for this table is restricted to those students for whom location data is available and students with at least one private school in their village. The sample is around $5 \%$ smaller than that in Table 4 (due to missing location data). All controls are as defined as in Table A.1. 
Table A.9: Balance by Medium of Instruction of Nearest Private School

\begin{tabular}{lccc}
\hline \hline & $\begin{array}{c}\text { Nearest } \\
\text { private school } \\
\text { is English } \\
\text { medium }\end{array}$ & $\begin{array}{c}\text { Nearest } \\
\text { private school } \\
\text { is Telugu } \\
\text { medium }\end{array}$ & $\begin{array}{c}\text { P-value for } \\
\text { difference }\end{array}$ \\
\cline { 2 - 4 } Normalized baseline Telugu score & {$[1]$} & {$[2]$} & {$[3]$} \\
Normalized baseline math score & 0.02 & -0.07 & 0.31 \\
Both parents have completed at least primary school & 0.02 & -0.05 & 0.49 \\
At least one parent has completed grade 10 & 0.32 & 0.23 & 0.00 \\
Scheduled caste & 0.37 & 0.31 & 0.04 \\
Household asset index & 0.33 & 0.32 & 0.69 \\
Observations & 3.21 & 3.10 & 0.13 \\
Notes: & 3,634 & 2,118 & 5,752 \\
All standard errors are clustered at the school level. All variables are defined as in Table A.1. The & & & The \\
sample comprises the voucher applicants for whom we also have GPS location data.
\end{tabular}


Tabel A.10: School and Teacher Characteristics by Private School Medium of Instruction

\begin{tabular}{|c|c|c|c|}
\hline & \multicolumn{3}{|c|}{ Panel A: School Characteristics } \\
\hline & $\begin{array}{l}\text { Private English } \\
\text { medium schools }\end{array}$ & $\begin{array}{l}\text { Private Telugu medium } \\
\text { schools }\end{array}$ & Difference \\
\hline & [1] & [2] & [3] \\
\hline Total enrollment & 353.22 & 214.33 & $138.89 * \star \star$ \\
\hline Total working days & 229.46 & 230.00 & -0.55 \\
\hline Pupil-teacher ratio & 19.26 & 14.49 & $4.76^{\star \star \star}$ \\
\hline Drinking water available & 0.99 & 0.97 & $0.022^{*}$ \\
\hline Functional toilets & 0.91 & 0.76 & $0.16^{\star \star \star}$ \\
\hline Separate functional toilets for girls & 0.79 & 0.72 & 0.073 \\
\hline Functional electricity & 0.90 & 0.83 & $0.068^{\star}$ \\
\hline Functional computers & 0.67 & 0.29 & $0.38^{\star \star \star}$ \\
\hline Functional library & 0.80 & 0.78 & 0.01 \\
\hline Functional radio & 0.12 & 0.13 & -0.01 \\
\hline \multirow[t]{2}{*}{ Observations } & 164 & 89 & \\
\hline & \multicolumn{3}{|c|}{ Panel B: Teacher Characteristics } \\
\hline Male & 0.24 & 0.25 & -0.01 \\
\hline Age & 33.27 & 31.97 & 1.29 \\
\hline Years of teaching & 5.48 & 4.48 & $1.00^{\star * *}$ \\
\hline Completed at least college or masters & 0.81 & 0.49 & $0.32^{\star \star \star}$ \\
\hline Teacher training completed & 0.42 & 0.22 & $0.21 * * *$ \\
\hline Come from the same village & 0.37 & 0.57 & $-0.20^{* \star *}$ \\
\hline Current gross salary per month (Rs.) & 2757.68 & 1919.07 & $838.61^{\star \star \star}$ \\
\hline \multirow[t]{2}{*}{ Observations } & 1215 & 720 & \\
\hline & \multicolumn{3}{|c|}{ Panel C: School Fees } \\
\hline Annual school fees charged per child (Rs./child) & 1768.25 & 1021.92 & $746.33^{\star * *}$ \\
\hline Observations & 156 & 88 & \\
\hline \multicolumn{4}{|l|}{ Notes: } \\
\hline \multicolumn{4}{|c|}{$\begin{array}{l}* p<0.1 ; * * p<0.05 ; * * * p<0.01 \text {. The sample for this table is restricted to schools and teachers in control villages across years } \\
2008 \text { through } 2012 \text {. In cases of multiple observations per school or teacher across different years, variable means are used } \\
\text { (so each teacher/school is one observation). School fees are measured in Rupees per student per year, trimmed at the 1st } \\
\text { and 99th percentiles to remove outliers. The actual number of observations for each regression may vary slightly within } \\
\text { columns based on the dependent variable. }\end{array}$} \\
\hline
\end{tabular}

